\title{
Los acuerdos de elección de foro en los contratos internacionales de consumo \\ Su eficacia en la Ley $\mathbf{N}^{\circ} 19.496$
}

\section{Choice of Court Agreements in International Consumer Contracts Their Efficacy Under Law No. 19.496}

\author{
PABLO A. GORNEJO*
}

\begin{abstract}
Resumen
El presente estudio se divide en dos secciones. La primera examina los fundamentos de los acuerdos de elección de foro, las funciones que desarrollan en la contratación internacional y las dificultades que genera su reconocimiento en los contratos entre partes con desigual poder de negociación, específicamente, en los contratos de consumo internacional. La segunda analiza las reglas nacionales de competencia judicial internacional aplicables a estos acuerdos. Con ese propósito, se expone primero el estado actual de la discusión acerca de su validez en Chile; para luego analizar la incidencia de la aplicación de las disposiciones de la Ley $\mathrm{N}^{\circ} 19.496$, sobre protección de los derechos de los consumidores (LPDC), en esta discusión. Aquí se estudian como posibles soluciones para determinar la validez de estos acuerdos la interpretación internacional de las reglas de competencia que contempla esta ley y el control que ella dispone sobre las cláusulas abusivas en los contratos de consumo. Lo anterior, para buscar una solución que armonice tanto los fines de protección del consumidor internacional, como el reconocimiento del carácter internacional de su relación de consumo, que permita reconocer la validez de estos acuerdos si se cumplen ciertos requisitos específicos.
\end{abstract}

Palabras clave: Competencia judicial internacional; Contratos internacionales de consumo; Elección de foro; Cláusulas abusivas; Acceso a la justicia

Abstract
This study is divided into two parts. The first part analyzes the rationale for choice
of court agreements, the roles they play in international contracts, and the difficulties
arising when recognizing them in agreements between parties with unequal
bargaining power, specifically in international consumer contracts. The second part
analyses the national rules of international jurisdiction applicable to these contracts.
Bearing this in mind, first, the current state of the discussion about their validity in
Chile is explained; then the effect in this discussion of applying the provisions of Law
No. 19.496 - on consumer rights protection (LPDC by its Spanish acronym), is
studied. The international interpretation of the rules of jurisdiction set forth by this
law, and the control it provides over abusive terms in consumer contracts are studied
as possible solutions to stablish the validity of these contracts. The foregoing, in order

* Universidad de los Andes, Chile (pacornejo@miuandes.cl). Artículo recibido el 22 de septiembre de 2020 y aceptado para su publicación el 2 de noviembre de 2020. 
to seek a solution that harmonizes, both, the purposes of international consumer protection and to recognize the international nature of their consumer relationship, which allows to consider these contracts as valid if some specific requirements are met.

Keywords: International jurisdiction; International consumer contracts; Choice of court; Abusive clauses; Access to justice

\section{INTRODUGGIÓN}

La existencia de intercambios entre privados que traspasan las fronteras nacionales o que involucran los principios del comercio internacional, da lugar a una categoría particular de contrato, la del contrato internacional. ${ }^{1}$ Sea que las partes durante su negociación o celebración lo adviertan o no, este tipo de contrato involucra a más de un ordenamiento jurídico. Por ello, estos contratos plantean interrogantes acerca del derecho que les resultará aplicable y acerca de la autoridad judicial o arbitral que estará llamada a conocer de las eventuales controversias que se produzcan entre sus partes contratantes.

La determinación del derecho y foro aplicables a estos contratos varía en los distintos sistemas jurídicos nacionales, porque ambas cuestiones son resueltas de manera independiente, y a veces diversa, por cada ordenamiento jurídico ${ }^{2}$ en sus normas nacionales de Derecho Internacional Privado. ${ }^{3}$ Para evitar estas divergencias, que crean incerteza jurídica para las partes, y armonizar el tratamiento de estas materias, los sistemas jurídicos adoptan medidas legales específicas, como permitir a las partes ejercitar su autonomía privada para elegir de manera anticipada el foro competente y la ley aplicable a sus contratos. ${ }^{4}$ De esta forma, los ordenamientos nacionales validan las elecciones de ley y foro que efectúan las partes, en sus contratos internacionales, pues se las considera una herramienta útil para alcanzar soluciones uniformes internacionalmente y proteger las legítimas expectativas de las partes respecto de los contratos que celebran. ${ }^{5}$ Estas elecciones

\footnotetext{
${ }^{1}$ El contrato es internacional cuando pone en juego los intereses del comercio internacional, o cuando los elementos de conexión del contrato lo conectan con diferentes Estados: PICAND y MAHú (2014), p. 398. Con todo, esta internacionalidad debe ser definida por cada foro: BRIGGS (2008), p. 7.

2 Virgós y Garcimartín (2007), p. 50; ScotTi (2017), pp. 183 y 198; Villarroel y ViLlarroel (2015), p. 371 .

${ }^{3}$ Esto conduce a que "existan diversos sistemas que se encuentran abiertos para la solución de los conflictos de los justiciables, quienes pueden acudir por razones legítimas o estratégicas a diferentes tribunales estatales en busca de justicia." VIRGÓs y GARCIMARTíN (2007), pp. 45-46.

4 BRIGgs (2008), p. 7; NyGH (1999), p. 47.

${ }^{5}$ Las partes en la litigación internacional afrontan riesgos relacionados con el foro donde que conocerá de la controversia, y con el reconocimiento y ejecución de las sentencias extranjeras. Puede ser difícil para una parte iniciar acciones o defenderse en un foro desfavorable, debido, entre otras causas, a los obstáculos jurisdiccionales o procedimentales del foro, o a la existencia de procedimientos paralelos. También puede ser difícil conseguir ejecutar una sentencia extranjera, fuera del foro del que proviene. En los contratos internacionales las partes anticipan estos problemas e intentan minimizar sus riesgos, mediante cláusulas que regulan los tribunales competentes y los remedios frente al incumplimiento de la contraparte. La minimización de estos riesgos
} 
suelen incluirse dentro de las cláusulas sobre resolución de controversias de los contratos y reducen la incertidumbre que afrontan las partes al celebrar un contrato internacional, pues les permiten razonablemente anticipar quién será la autoridad - judicial o arbitralllamada a conocer de un conflicto relativo a ese contrato, y/o la normativa de fondo que se aplicará a su decisión.

Los acuerdos de elección de foro ${ }^{6}$ son pactos o convenios celebrados por las partes — sea mediante la inclusión de una cláusula especial incorporada en un contrato internacional, o bien a través de una convención autónoma, coetánea o posterior al nacimiento de la controversia-, por medio de los cuales las partes definen cuál será el foro llamado a conocer de las controversias relativas a una relación jurídica concreta, y excluyen otros foros potencialmente competentes para resolverlas. Como se puede anticipar, al igual a como ocurre con la cláusula arbitral, ${ }^{7}$ estos acuerdos constituyen pactos de carácter material, ${ }^{8}$ que tienen un doble efecto procesal, pues, mientras por una parte afirman la jurisdicción de los tribunales de un determinado foro - prorrogatio for ${ }^{9}$ - , por otra, inhiben la actuación de los tribunales del foro excluido, en virtud de la derogatio fori. ${ }^{10}$

La expansión en el uso de estos pactos de elección de foro en la práctica comercial internacional responde también a otras ventajas que otorgan a las partes. ${ }^{11}$ Dentro de ellas, ${ }^{12}$ se suele invocar que los pactos de elección de foro pueden permitir una mayor equidad en la elección de foro; ${ }^{13}$ una mayor proximidad del tribunal elegido con el conflicto, o una

depende de la efectividad de estos acuerdos de elección de foro en los distintos Estados conectados con el contrato internacional. FENTIMAN (2015), pp. 6, 42-44. NYGH (1999), pp. 2-3.

${ }^{6}$ En este artículo preferimos usar la expresión "acuerdos de elección de foro" — en consonancia con el Convenio de La Haya de 2005 - con el propósito de enfatizar el carácter convencional que tiene la atribución de competencia realizada por las partes a las autoridades de un determinado foro, para conocer de las controversias que se produzcan respecto de una relación jurídica concreta. Con todo, debemos dejar constancia que, en Chile, la expresión más comúnmente usada para designarlos es "sumisión expresa", de acuerdo con la terminología establecida en el Código de Bustamante. Guzmán (1997), pp. 547 ss.; Villarroel y Villarroel (2015), p. 402; RAMíREZ (2013), p. 262.

${ }^{7}$ A pesar de que tanto la cláusula arbitral como el acuerdo de elección de foro inciden en la autoridad llamada a conocer de una controversia, existe una mayor reticencia a aceptar las elecciones de foro extranjero realizada por las partes, porque se considera que son pactos que expresan un desafío más directo a la jurisdicción de la autoridad estatal nacional. NYGH (1999), p. 15.

${ }^{8}$ VIRGÓs y GARCIMARTín (2007), p. 279. FENTIMAN agrega que el acuerdo obliga contractualmente a las partes a recurrir al foro designado y a no iniciar procedimientos en un foro distinto, énfasis que luego vincula con los remedios materiales a que pueden acceder en caso de incumplimiento. FENTIMAN (2015), p. 44.

${ }^{9}$ Virgós y Garcimartín (2007), p. 271; NYGH (1999), p. 15; ROMERO (2017), p. 165.

${ }^{10} \mathrm{El}$ efecto del pacto dependerá de la voluntad de las partes: "Nada impide [...] que las partes quieran un efecto solamente prorrogatorio o solamente derogatorio." VIRGÓs y GARCIMARTín (2007), p. 274; GARAU (2008), pp. 32-33; FENTIMAN (2015), p. 61; ROMERO (2017), p. 165; NYGH (1999), p. 15.

${ }^{11}$ Como es el reconocimiento de que las partes son quienes se encuentran en mejor posición para definir su propio interés y determinar la autoridad judicial que conocerá de la controversia; además de razones de orden práctico, como reducir la incertidumbre, aumentar la previsibilidad y desincentivar comportamientos oportunistas. VIRGÓS y GARCIMARTín (2007), p. 275., HOOK (2016), p. 59.

12 Para una enunciación de sus ventajas, Villarroel y Villarroel (2015), pp. 405-406.

${ }^{13}$ Boggiano (2001), p. 149. 
designación de un tribunal con mayor experiencia para conocer de la materia controvertida; ${ }^{14}$ u otorgar una certeza previa a las partes acerca de que, en ese foro, será reconocida la elección de derecho que efectuaron en su contrato, ${ }^{15}$ o que en él resultarán ejecutables las cláusulas que ellas incorporaron en el contrato en virtud de su autonomía material; o bien, asegurar el carácter neutral del tribunal llamado a conocer del conflicto, ${ }^{16}$ o la adecuación de las reglas procedimentales del foro a la materia controvertida; o que la determinación de la jurisdicción competente evite que una de las partes busque radicar la controversia ante un foro que le reporte beneficios injustos, por medio del forum shopping. ${ }^{17}$

Con todo, si bien estas razones de orden práctico permiten explicar la difusión de estos acuerdos en la contratación internacional, su fundamentación última se encuentra en la autonomía de las partes y en el reconocimiento jurídico de su poder privado de configuración normativa, que está en la base del modelo de justicia privada en materia de competencia judicial internacional. ${ }^{18}$ En este sentido, podemos afirmar que en la contratación internacional - al igual que ocurre en el derecho privado - la aceptación de la autonomía privada de las partes en materia jurisdiccional es un valor en sí mismo, digno de reconocimiento y que debe estar en la base de cualquier sistema jurídico. Lo anterior no sólo porque responde a una exigencia de carácter ético, sino porque además permite situar a la persona como un actor libre e independiente en el plano internacional, ${ }^{19}$ en consonancia con una comprensión verdaderamente internacional de sus relaciones jurídicas. Por la misma razón, esta aceptación pone énfasis en una comprensión de la jurisdicción centrada en la función de suministrar una tutela judicial efectiva inter privatos, en contra de aquellas aproximaciones centradas en una concepción reductiva de jurisdicción, entendida como un poder exclusivo y soberano del Estado.

\footnotetext{
14 Un ejemplo, es la percepción de Londres como centro idóneo para la resolución de disputas comerciales internacionales y el rol de su Commercial Court como un foro internacional neutral, eficiente, justo y orientado comercialmente en sus decisiones. FENTIMAN (2015) pp. 7-8.

15 "Cuando las partes deciden acerca de la jurisdicción de los tribunales que van a conocer de un determinado litigio, en última instancia su acuerdo también incide sobre las normas materiales que van a ser aplicables a la relación litigiosa. La elección por las partes de los tribunales de un país conlleva la aplicación de su sistema conflictual y la consiguiente designación de un concreto ordenamiento jurídico.” GARAU (2008), p. 34.

16 Boggiano (2001), p. 151.

17 Boggiano (2001), pp. 149-150.

${ }^{18}$ Mientras el modelo de soberanía se fija en la jurisdicción como poder y ve la justicia como una expresión de ese poder soberano del Estado; en el modelo de justicia privada el énfasis está puesto en la jurisdicción como función, en la tarea de suministrar una tutela judicial efectiva inter privatos. Por esta razón, a diferencia de lo que ocurre en el modelo de soberanía, en el modelo de justicia privada se reconoce la autonomía de la voluntad de los particulares y la configuración como principio regulador de la proximidad razonable del asunto con el foro. Todo lo anterior permite, a su vez, avanzar en un modelo de jurisdicción de carácter dispositivo. VIRGÓS y GARCIMARTín (2007), p. 71. En el caso chileno, la doctrina que niega validez a estos acuerdos se sustenta precisamente en esta visión soberana de la jurisdicción.
}

19 HoOK (2016), p. 59. 


\section{LA ELECGIÓN DE FORO Y LOS LÍMITES A LA AUTONOMÍA PRIVADA}

Es universalmente aceptado que los ordenamientos jurídicos pueden poner límites a la autonomía de la voluntad de las partes y, en concreto, a las elecciones de foro convencionales, para proteger otros intereses jurídicos superiores. En efecto, esta autonomía opera a través del contrato, y todo contrato requiere de un cuerpo de reglas y principios jurídicos que definan su sentido y límites. ${ }^{20}$ Por esta razón, se ha admitido que el respeto de la autonomía privada es compatible con su limitación legal cuando existe un objetivo primordial de interés público. $^{21}$

De este modo, en el moderno derecho de los contratos, se han establecido límites que buscan proteger el correcto ejercicio de la autonomía privada por las partes contratantes. Esto ocurre con las restricciones que buscan asegurar la libertad contractual cuando existe un marcado desequilibrio en su poder negociador. Estos límites pueden aplicarse a los acuerdos de elección de foro en contratos internacionales cuando ellos no son el resultado de una verdadera negociación entre las partes, sino que vienen impuestos por una de ellas. ${ }^{22}$ En estos casos puede resultar cuestionable que estos acuerdos manifiesten una elección equitativa del foro, o que haya una razonable y justa proximidad o conexión entre la jurisdicción escogida y el conflicto. Esto porque siempre existe el riesgo de que estos acuerdos sean usados por la parte más fuerte de la relación, con el propósito de imponer la competencia de los tribunales de un determinado Estado de su conveniencia, en desmedro de los intereses de la parte más débil. ${ }^{23}$ Con todo, la asimetría en el poder negociador de las partes, o la sola existencia de cláusulas de adhesión que una parte deba aceptar, no debería llevarnos necesariamente a cuestionar la validez de las cláusulas de elección de foro. ${ }^{24}$ Generalizar este cuestionamiento sería incompatible con la buena fe contractual, que exige no desconocer aquello que fue libremente convenido en el contrato, ${ }^{25}$ e introduciría elementos de incertidumbre en el contrato internacional, incompatibles también con las necesidades actuales del tráfico jurídico y comercial internacional.

La regla general y primordial en materia de contratos debe ser reconocer la validez de los acuerdos y compromisos de las partes, aunque se trate de contratantes que no tengan el mismo poder negociador, o que no cuenten con la misma información. Por ello, cuestionar la validez de las cláusulas de elección de foro sólo será justificado en aquellos contratos donde

\footnotetext{
${ }^{20} \operatorname{HOOK}$ (2016), p. 16.

21 BRIGGS (2008), p. 12.

22 Todo sistema que reconozca a las partes la facultad de definir el foro competente debe garantizar que esa elección se produzca en una situación de equidad entre ellas. De no ser así, el propio legislador debe prever las limitaciones a esa facultad. GONZÁLEZ y MARTín (2011), p. 171.

23 Tomé y García-Luben (2011), p. 214; Briggs (2008), p. 12.

${ }^{24}$ Especialmente si consideramos que el contrato de adhesión puede implicar ventajas para el consumidor, por la disminución del precio de los bienes o servicios contratados. DE LA MAZA (2012a), p. 10. Por esta razón, creemos que lo problemático no es la inclusión de la cláusula en un contrato de adhesión, sino la eventual imposibilidad de la parte débil de conocer previamente sus efectos, o el desequilibrio que produzca su inclusión en el contrato en detrimento de ella misma.

25 CORRAL (2006), p. 197.
} 
exista estructuralmente una asimetría entre las partes, que lleve a que una de ellas sea calificada como "débil" y por tanto merecedora de una especial protección por parte del ordenamiento jurídico. ${ }^{26}$ Esto ocurre, por lo general, en las relaciones contractuales entre proveedores y consumidores y ha dado lugar al desarrollo de un derecho ad hoc, el moderno derecho de consumo.

El desarrollo de estas normativas de protección al consumidor en las legislaciones nacionales es un fenómeno propio de la segunda mitad del siglo veinte. ${ }^{27}$ Cuestionando el modelo decimonónico de contrato ${ }^{28}$ - concebido en torno a la idea de acuerdo libremente negociado-, por no adecuarse a las condiciones modernas de contratación en masa, ${ }^{29}$ las legislaciones nacionales comenzaron a adoptar estatutos de protección de los derechos del consumidor, por considerarlo la parte más débil de la relación contractual. ${ }^{30}$ Esta protección establecida para contratos nacionales, también se extendió a los contratos internacionales de consumo, ${ }^{31}$ que han aumentado crecientemente a raíz de los procesos de integración económica, el mayor desarrollo del comercio internacional y la masificación de los medios técnicos que facilitan los intercambios de bienes y servicios a nivel internacional. ${ }^{32}$ Surgió entonces la necesidad de definir y proteger el interés del consumidor en el contexto de los contratos internacionales con proveedores situados en otro país.

Este desarrollo afectó el reconocimiento de los acuerdos de elección de foro en los contratos de consumo internacionales. ${ }^{33}$ En efecto, la aplicación práctica de estos acuerdos

${ }^{26}$ Es difícil encontrar una relación contractual en la que las partes se encuentren en una posición de igualdad al momento de negociar. Por ello se discute quiénes deben quedar comprendidos dentro de la categoría de "parte débil", y si deben incluirse en ella a los pequeños comerciantes que carecen de poder económico, pero son especialistas dentro de su ámbito de actuación. Álvarez (1992), p. 41.

27 TAPIA (2017a), pp. 79-80; ISLER (2019a), pp. 61-63; GUARDANS (1992), pp. 319 ss.

28 TAPIA (2017a), p. 79.

29 PiZARro (2012), pp. 49-51.

30 ISLER (2019a), p. 98.

31 Esto obliga a examinar cuáles son los efectos de la mayor intervención de la autoridad nacional en los contratos de consumo internacional y las limitaciones que ella les impone. NyGH (1999), pp. 28-30. Por contrapartida, los principales instrumentos internacionales en materia de contratación deliberadamente excluyen al consumidor de sus regulaciones, debido a la ausencia de normas de protección comunes en los diversos Estados. ScOTTI (2017), pp. 782-784.

32 En particular, se destaca la adopción de la contratación electrónica, que confiere un incremento sustancial al tráfico de productos y servicios, sin estar ligados a fronteras nacionales. Esto supone un importante reto para la concepción clásica del derecho internacional privado, que, al ser nacional y territorial, fuerza a una ordenación espacial de relaciones jurídicas, que hoy no es posible. LeIBLE (2017), pp. 14-15. Además, se constata un aumento de la presencia de elementos internacionales en las relaciones privadas de consumo. KLEIN (2013), p. 1 .

33 Proteger al consumidor respecto de los efectos nocivos de los acuerdos de elección de foro que pudieren serle impuestos reviste una particular relevancia, pues estos acuerdos son frecuentes en los contratos de consumo internacional. Por el contrario, en los contratos internacionales celebrados entre comerciantes, es más frecuente el pacto de cláusulas arbitrales negociadas por las partes. Aunque existen ámbitos, como el financiero, bancario, naviero y reaseguros donde la elección de un tribunal ordinario es relevante. ÁlvAREz (1992), p. 140 y FENTIMAN (2015) p. 8. 
en los litigios de consumo internacional ${ }^{34}$ puede afectar el derecho a la tutela judicial efectiva del consumidor, por los costos y dificultades que puede implicarle litigar ante un tribunal extranjero. Con todo, este objetivo de proteger al consumidor debe reconocer ciertos límites, pues por sí solo no justifica sacrificar los intereses de su contraparte imponiéndole un foro que no pudo prever al celebrar el contrato, o que no tiene conexión con la relación contractual.

Las reglas que definen la competencia judicial internacional deben ser razonables y permitir una adecuada distribución de las controversias entre las distintas jurisdicciones, que garantice el acceso a la justicia de todas las partes de la relación litigiosa. Por eso, la solución de esta eventual asimetría de las partes contratantes exige mantener un equilibrio entre el derecho fundamental de acceso a la justicia en su dimensión privada internacional para ambas partes del contrato de consumo, ${ }^{35}$ y las exigencias de la razonable proximidad entre el foro y el litigio, que garantice que ellas puedan exigir sus derechos y hacer valer sus medios de defensa adecuadamente. ${ }^{36}$

En efecto, la previsibilidad del foro competente es un principio que debe informar todo sistema jurisdiccional y que debe garantizarse a las partes, juntamente con el principio de legalidad y de tutela judicial efectiva. ${ }^{37}$ Estos principios obligan a considerar los eventuales problemas de acceso a la justicia que puede experimentar el consumidor como consecuencia de un foro "impuesto" contractualmente por la contraparte y a buscar los medios para asegurarle ese acceso. Con este objetivo, se han establecido en ciertos sistemas jurídicos los llamados foros de protección. ${ }^{38}$ Estos foros de protección resguardan los intereses del consumidor, considerado como la parte "débil" en la relación jurídica, de dos maneras: en primer lugar, establecen una regla especial de competencia residual para favorecer el acceso

${ }^{34}$ Esta situación, problemática en el ámbito nacional, puede tornarse crítica en el internacional, debido a las dificultades que implica litigar en otro foro extranjero. SCOTTi (2017), p. 190. Además, la escasa cuantía de las pretensiones desincentiva a los consumidores para recurrir a esa jurisdicción. KLEIN (2013), p. 4.

35 DREYZIN (2015), p. 158.

36 "El principio de la defensa de la tutela judicial efectiva significa, pues, que la competencia judicial internacional de los tribunales de un país no debe extenderse a casos que carezcan de 'vinculación' o 'contactos' con dicho país, por el contrario, las partes deben poder acceder a los mismos tribunales cuando el asunto presente 'vínculos suficientes' con ese país." Villarroel y Villarroel (2015), pp. 374. Para un desarrollo del concepto de tutela judicial efectiva en el derecho chileno y su relación con el acceso a la jurisdicción, véase GARCÍA y CONTRERAS (2005), pp. 244-250. En el caso chileno, este principio es una garantía implícita en el artículo 19 N³ de la Constitución, que reconoce a todas las personas la igual protección de la ley en el ejercicio de los derechos. Este principio podría verse afectado porque el reconocimiento del efecto derogatorio del acuerdo de elección de foro extranjero implicaría que los tribunales nacionales carecerían de jurisdicción para poder conocer y juzgar una determinada controversia, e importaría, correlativamente, que los justiciables carecerían de una acción ante el foro chileno. COLOMBO (2004), pp. 584 y ss. Por esta razón, resulta importante que la intervención en otro foro sea posible, a fin de evitar una privación del acceso a la justicia de estos justiciables. Véase también, VIRGÓs y GARCIMARTíN (2007), p. 67-68.

37 DREYZIN (2015), p 158.

38 Sobre el particular, v. artículo 18 del Reglamento (UE) N $1215 / 2012$, relativo a la competencia judicial, el reconocimiento y la ejecución de resoluciones judiciales en materia civil y mercantil (Reglamento Bruselas I bis); artículo 16 del Convenio relativo a la competencia judicial, el reconocimiento y la ejecución de resoluciones judiciales en materia civil y mercantil de 2007 (Convenio de Lugano); artículo 114 inc. $1^{\circ}$ de la Ley federal sobre el derecho internacional privado suiza; y el artículo 2654 del Código Civil y Comercial argentino. 
a la justicia del consumidor, garantizándole su derecho a litigar ante un foro próximo; ${ }^{39} \mathrm{y}$, en segundo lugar, restringen los efectos de los acuerdos de elección de foro cuando van en desmedro de sus derechos. ${ }^{40}$ Con todo, para que el consumidor se encuentre amparado por estos foros de protección, es necesario que concurran ciertas condiciones. La primera y más evidente, es que se trate jurídicamente de un consumidor, en conformidad con los conceptos que emplea la normativa del foro de protección. ${ }^{41} \mathrm{Y}$ la segunda, es que la aplicación del foro de protección sea de alguna manera prevista y conocida por el proveedor al tiempo de celebrar el contrato, puesto que él asume el riesgo de la aplicación de esta regla de excepción. Este conocimiento del proveedor es relevante, porque la aplicación del foro de protección implica en la práctica su renuncia a ser demandado en su foro natural que, por lo general, será el de su domicilio o residencia habitual. ${ }^{42}$ Debido a lo expuesto, se ha justificado que el proveedor pueda ser demandado ante el forum actoris, es decir, el foro en el cual o hacia el cual ha dirigido su oferta, ya que se ha considerado que por el hecho de dirigir su actividad comercial al lugar donde se encuentra el consumidor demandante, estaría asumiendo, como parte de su misma actividad comercial, el riesgo de un litigio ante ese foro extranjero. ${ }^{43}$

39 ScotTi (2017), p. 209. En definitiva, el forum actoris del consumidor reduce sus costes de acceso a la jurisdicción. VIRGÓS y GARCIMARTÍN (2007), p. 167.

${ }^{40}$ En el caso de la Unión Europea, el consumidor tiene la facultad de demandar en el foro del Estado miembro donde tenga su domicilio, o donde esté domiciliado el proveedor. La elección de foro procede sólo si es posterior al nacimiento del litigio y permite al consumidor demandar ante otros órganos jurisdiccionales, y cuando se elija la jurisdicción del foro donde el consumidor estaba domiciliado al tiempo de la celebración del contrato. v. art. 18 y 19 Reglamento Bruselas I bis y VIRGÓs y GARCIMARTín (2007), pp. 166-175; GONZÁLEZ y MARTíN (2011), pp. 162-173. El Convenio de Lugano contempla una solución similar en sus artículos 15 y 16 . En el caso suizo, la Ley federal sobre el derecho internacional privado, dispone en su artículo 114 inc. $2^{\circ}$ que el consumidor no puede renunciar anticipadamente al foro de su domicilio o residencia habitual. Para un análisis comparado de la aplicación de esas reglas, véase FORNAGE (2011), pp. 242-259 y 290 a 321 . En el mismo sentido, el artículo 2654 del Código Civil y Comercial argentino de 2015 reconoce al consumidor la facultad de interponer su acción ante foros alternativos, el de los jueces del lugar de celebración del contrato, de la prestación de los servicios, de la entrega de bienes, del cumplimiento de la obligación de garantía, del domicilio del demandado, o del lugar donde el consumidor realiza actos necesarios para la celebración del contrato, pero no admite la elección de foro. Como señala LóPEZ, el fundamento de esta prohibición de elección de foro se encuentra en la prevención del abuso o de las cláusulas predispuestas. Por esta razón, como la norma no distingue entre el acuerdo celebrado antes o después de producido el daño, "la mejor interpretación es que ni siquiera en este último caso sería posible porque se trata de un estatuto protectorio y porque además la ley no distingue.” LÓPEZ (2015), p. 401.

${ }^{41}$ En el caso del Reglamento 1215/2012, se recurre a un concepto autónomo de consumidor, distinto al previsto por cada normativa nacional de los países miembros de la Unión Europea. v. GONZÁLEZ y MARTíN (2011), pp. 166-168; VIRGÓS y GARCIMARTíN (2007), pp. 168-169.

42 GonZÁLEZ y MARTín (2011), pp. 164-166.

${ }^{43}$ En este sentido, exige el artículo $17 \mathrm{~N}^{\circ} 1$ letra c) del Reglamento Bruselas I bis que el proveedor "ejerza actividades comerciales o profesionales en el Estado miembro del domicilio del consumidor o, por cualquier medio, dirija tales actividades a dicho Estado miembro o a varios Estados miembros, incluido este último, y el contrato esté comprendido en el marco de dichas actividades. Véase VIRGÓs y GarcimarTín (2007), p. 170. Con todo, la solución no ha estado exenta de críticas, sobre todo por parte de las empresas que desarrollan el comercio electrónico, quienes consideraran que afecta el desarrollo de su actividad. GONZÁLEZ y MARTíN (2011), p. 166. Una solución similar se contempla en el artículo 15 №1 letra c) del Convenio de Lugano. 
Los foros de protección y los acuerdos de elección de foro en materia de consumo internacional no han sido regulados por nuestro legislador, ${ }^{44}$ y prácticamente no han sido objeto de análisis por parte de la doctrina nacional, ${ }^{45}$ pese a la creciente apertura al comercio exterior de la economía chilena y consecuente aumento de contratos de consumo internacional con parte domiciliada o residente en Chile. ${ }^{46}$ Existe además escasa jurisprudencia nacional respecto de la protección internacional del consumidor. ${ }^{47}$ Por esta razón, es relevante examinar su validez y eficacia jurídica en Chile cuando se incorporan en los contratos internacionales de consumo y analizar si, pese a la ausencia de una norma legal específica reguladora de estos acuerdos, una interpretación armónica y teleológica de las disposiciones de la Ley N¹9.496 puede determinar si son válidos y bajo qué condiciones. Además, cabe estudiar si esta ley permite conciliar adecuadamente los intereses de las dos partes involucradas en una relación de consumo internacional en lo que respecta a su acceso a la justicia.

Al desarrollar este análisis, se afirmarán tres hipótesis conexas: que los contratos de consumo internacional no excluyen la aplicación de las disposiciones de la LPDC en aquellos casos en que existan vínculos relevantes entre el contrato y el ordenamiento jurídico chileno; que es relevante en las relaciones de consumo internacional asegurar el acceso a la justicia del consumidor; y que, por ello, el reconocimiento de la autonomía privada, expresada en la aceptación de los acuerdos de elección de foro, debe ser armónico con el carácter tuitivo o protector de la normativa de consumo.

Finalmente, debemos hacer presente que este análisis se centrará en la eficacia de la sumisión expresa a un tribunal ordinario extranjero a la luz de la LPDC, y no analizará el arbitraje internacional de consumo, debido a que éste tiene un tratamiento especial dentro

\footnotetext{
${ }^{44}$ Excepcionalmente, según consta en el Primer Informe de la Comisión de Economía del Senado en el contexto de la discusión de la Ley $N^{\circ} 21.081$, se plantearon soluciones destinadas a proteger a los consumidores en el ámbito internacional, en lo que concierne a la elección de foro y al derecho aplicable. En particular, la senadora Pérez presentó una indicación para incorporar al artículo 16 de la LPDG un nuevo literal, que declaraba abusiva toda cláusula que estableciera "como competente a un tribunal extranjero para conocer y resolver todas aquellas controversias que se produzcan con ocasión de la ley." Sin embargo, la Comisión solicitó su retiro, puesto que se consideró que conforme con lo indicado por el Ejecutivo era posible declarar el carácter abusivo de la cláusula conforme con lo dispuesto en el artículo 16 letra g) de la LPDC, o bien de las nuevas reglas sobre competencia. 45 En relación con la aplicación de las reglas de derecho internacional privado a las relaciones de consumo internacional, véase: SEVERín (2019), pp. 959-980.

${ }^{46}$ Esta situación ha sido calificada como anómala, pues mientras por una parte se presenta una economía abierta al comercio exterior, por otra no se ha producido una efectiva reforma de la normativa interna en materia de derecho internacional privado que confiera un sustento sólido a ese desarrollo. FERNÁNDEZ (2005), pp. 106107. En similar sentido, EsPLUGUES (2014), pp. 298-304.

47 Rivas Nielsen con Med El Elektro (2013). En el caso en cuestión, se promovió una demanda de indemnización de perjuicios en contra de una sociedad con domicilio en Austria - en su calidad de fabricante de unos implantes cocleares defectuosos - y de una sociedad con domicilio en Argentina - en su calidad de distribuidora de los referidos implantes - la Corte Suprema rechazó la excepción de falta de jurisdicción, por considerar que la controversia se promovió dentro del territorio de la república, en los términos del artículo $5^{\circ}$ del Código Orgánico de Tribunales (COT), pues el hecho ilícito se produjo en Chile, cuando se implantaron en el paciente los dispositivos defectuosos. Sin embargo, en el proceso no se discutió la eventual aplicación de las normas de consumo.
} 
de la normativa de consumo, ${ }^{48}$ que acarrea problemas particulares en la definición de la arbitrabilidad de la controversia. ${ }^{49}$ Tampoco estudiará la protección de los intereses colectivos o difusos en los contratos de consumo internacional, pues independientemente de la necesidad de intervención del tribunal chileno para proteger los intereses involucrados en esta clase de procesos, sus características impiden que alguien cuente con una representación suficiente para someter contractualmente y de forma anticipada su conocimiento a un foro determinado.

\section{II. ¿CÓMO SE PLANTEA LA SITUAGIÓN EN GHILE?}

En nuestro sistema legal, la validez de las cláusulas incorporadas en los contratos de consumo está regulada principalmente en las disposiciones de la LPDC, que norma tanto cuestiones sustantivas como procesales de las relaciones de consumo. El análisis y comprensión adecuada de las disposiciones de esta ley en su aplicación a las relaciones internacionales de consumo, requiere, sin embargo, como paso previo, analizar brevemente, las reglas chilenas de competencia judicial internacional y las cuestiones que se han suscitado con ocasión de la validez de los acuerdos de elección de foro. Esto es necesario porque el problema de fondo abordado en este artículo - la eficacia de la sumisión expresa a un tribunal extranjero, a la luz de la LPDC- carecería de sentido si nuestro ordenamiento declarase nulos estos pactos de sumisión o de elección de foro. Además, es relevante porque existen diferentes posturas en nuestra doctrina nacional acerca del alcance y límites de la jurisdicción internacional, las que afectan la interpretación y aplicación de las disposiciones de la LPDG.

\section{1 ¿Son válidos los acuerdos de elección de foro extranjero en Chile?}

Si prescindimos de la aceptación de los pactos de sumisión internacional regulada en el artículo 318 del Código de Bustamante - que, como tratado vigente, sólo se aplica entre Estados ratificantes y en la medida que contraríe el derecho interno chileno, atendida la particular reserva de que fue objeto--, la legislación chilena no contiene normas generales que regulen la validez de los acuerdos de elección de foro en el ámbito internacional. Aunque una doctrina minoritaria, aplicando el art. 1462 del Código Civil $(\mathrm{CG}),{ }^{50}$ afirma que estos pactos de elección de foro adolecen de ilicitud en su objeto porque versan sobre una materia propia del derecho público, como es la determinación de la jurisdicción de un tribunal para

\footnotetext{
48 Véanse los art. 16 inc. $2^{\circ}$ y $3^{\circ}$ LPDG.

${ }^{49}$ En particular, de acuerdo con lo dispuesto en el artículo V, 2, letra a) de la Convención de Nueva York de 1958, sobre el reconocimiento y ejecución de las sentencias arbitrales extranjeras.

50 Como correctamente señalan AGUIRREzÁBAL et al., el hecho de que los acuerdos de prórroga de jurisdicción sean precisamente el ejemplo de pacto contrario al derecho público chileno demuestra una cierta desconfianza del codificador hacia la figura, desconfianza que ha sido superada por la doctrina, principalmente por las exigencias que plantea el comercio moderno. Con todo, la postura que se adopte acerca de la validez o nulidad de estos acuerdos de elección de foro dependerá en gran medida de si se concibe la jurisdicción como un poder público inderogable, o como un elemento que puede ser objeto de disposición por la autonomía privada. AgUiRREZÁBAl et al (2011), pp. 440-443. Véase también, Romero (2017), pp. 165-169.
} 
conocer de una controversia; ${ }^{51}$ actualmente, la mayor parte de los autores nacionales aceptan su validez en el derecho chileno. ${ }^{52}$ Lo anterior, pese a que no es pacífica la aceptación de la voluntad de las partes como regla general para definir la competencia judicial internacional en materia de contratos. ${ }^{53}$

En particular, este reconocimiento de las elecciones de foro realizadas por las partes se sustenta en el rol preponderante que tiene en Chile la autonomía privada en la contratación internacional. A esta conclusión se llega a partir de una interpretación sistemática de varias normas vigentes: los Considerandos $1^{\circ}$ y $2^{\circ}$ del D.L. $N^{\circ} 2.349$, que declaran que los pactos de elección de tribunal extranjero en contratos internacionales son estipulaciones lícitas y conformes con el derecho nacional, al tiempo que reconocen su frecuente aplicación en los contratos internacionales celebrados entre privados; ${ }^{54}$ lo dispuesto en el artículo 318 del Código de Bustamante, que consagra como norma general en materia de conflictos civiles y mercantiles la competencia de los tribunales a quienes los litigantes se sometan expresa o tácitamente; la Ley $\mathrm{N}^{\circ} 19.971$, que permite a las partes someterse a un arbitraje que tendrá su sede en el extranjero; 55 y, finalmente, los artículos 242 a 245 del Código de Procedimiento Civil (CPG), que establecen los requisitos para reconocer la validez en Chile de decisiones judiciales extranjeras. Todas estas normas permiten reforzar la interpretación de que la ilicitud de objeto del pacto del artículo 1462 CG sólo tendría lugar en aquellos casos en que las partes efectivamente se sometieran a una jurisdicción no autorizada por la ley nacional, como se desprende del tenor literal de este artículo, y no se aplicaría a las elecciones de foro extranjero aceptadas por la ley chilena.

\footnotetext{
${ }^{51}$ Esta línea argumentativa ha sido recogida por alguna antigua jurisprudencia (v. CORTE SUPREMA [1905]) y por autores como HAMILTON (1966), pp. 364-365. Con todo, quien más recientemente ha insistido en esta interpretación es COLOMBO. Él afirma que el ejercicio de la función jurisdiccional pertenece exclusivamente a los tribunales establecidos por la ley, cuya fuerza deriva de la soberanía misma. CoLOMBo (1991), pp. 43 y ss. Sobre esta misma base, afirma en una obra posterior que "En el derecho interno, desde el momento en que todo tribunal goza de una parte de ella, no es posible la prórroga de la jurisdicción. En el derecho internacional ello tampoco es posible, ya que es de toda evidencia que la jurisdicción que el Estado, inspirándose en los supremos intereses nacionales, se atribuye a sí mismo, no puede ser objeto de disposición por parte de los litigantes." COLOMBO (2004), p. 63.

52 Villarroel y Villarroel (2015), pp. 403-406; Canelo (2014), pp. 43-52; Ramírez (2013) pp. 262-266; Monsálvez (2010), pp. 344 y 345; Gallegos (2010), pp. 144-148; GuZMÁn (2008), pp. 219-224; Monsálvez (2008), pp. 225-239; GuZMÁN (1997) pp. 547-550. Esta interpretación ha comenzado a permear la doctrina civil, como queda reflejado en las últimas versiones de la obra de DoMíNGUEZ sobre el negocio jurídico, Domínguez (2012), p. 135.

53 En este sentido, principalmente Villarroel y Villarroel (2015), pp. 394-396 y 398 ss.

${ }_{54}$ D.L. No 2.349 de 1978, que establece normas sobre contratos internacionales para el sector público, véase también art. $1^{\circ}$ del mismo cuerpo legal.

${ }^{55}$ En particular, esto resulta de lo dispuesto en los artículos 35 y 36 de la Ley $\mathrm{N}^{\circ} 19.97$ 1, sobre arbitraje comercial internacional, que reconocen el carácter vinculante de los laudos arbitrales extranjeros que pretendan ser reconocidos o ejecutarse en Chile, sin importar el país del cual provengan. AGUIRREZÁBAL et al (2011), p. 462. En el caso del arbitraje, la noción que delimita las competencias entre las autoridades judiciales de un país y los árbitros es la arbitrabilidad objetiva (art. 36.1 letra b) número ii) de la Ley $\mathrm{N}^{\circ} 19.971$ y artículo V, 2, letra a) de la Convención de Nueva York de 1958), pues afirmar que una materia es inarbitrable implica una reserva de jurisdicción en beneficio de la jurisdicción estatal. Véase CAIVANO (2011), pp. 368 y ss.
} 
Por todas estas razones, la doctrina afirma que la regla general en la legislación chilena es la admisión de los acuerdos de elección de foro extranjeros, pues nuestras leyes reconocen la competencia de jurisdicciones extranjeras, salvo en aquellas materias excepcionales en que la ley chilena establece una jurisdicción exclusiva de los tribunales chilenos, por medio de normas nacionales imperativas de aplicación necesaria. ${ }^{56}$ Esto puede fundamentarse en lo dispuesto en el artículo 245 N² del CPG, que permite denegar el reconocimiento en Chile de los fallos extranjeros cuando se oponen a la jurisdicción nacional, oposición que se daría cuando la causa debería haber sido conocida y fallada necesariamente por los tribunales chilenos. ${ }^{57}$ Esta es la línea jurisprudencial que ha seguido la Corte Suprema en los últimos años, ${ }^{58}$ la que coincide con la interpretación de las normas sobre jurisdicción que ha hecho el Tribunal Constitucional. ${ }^{59}$

En conclusión, pese a la ausencia de una regla general que valide los acuerdos de elección de foro extranjero en contratos internacionales en nuestro derecho, existe una línea argumentativa fundada en la importancia de la autonomía privada en la contratación internacional, que reconoce la validez de estos acuerdos, siempre que no se trate de negocios puramente nacionales, ${ }^{60}$ o de uno aquellos casos en que la jurisdicción de los tribunales

56 En el considerando $4^{\circ}$ de A.f. Broom con Exportadora Frutícola (1999) la Corte Suprema señala que "efectivamente, el artículo 929 del Código de Comercio dispone que las normas legales sobre contrato de transporte marítimo son imperativas para las partes, salvo cuando la ley expresamente disponga lo contrario, precepto del que se desprende que, en general, aquellas normas contienen elementos esenciales del contrato y que, por consiguiente, no pueden ser excluidos ni modificados por los contratantes; así entonces, debe entenderse que las reglas de competencia que determinadamente se contienen en los artículos 1032 a 1035 del citado Código no están entregadas a la voluntad o arbitrio de las partes, de manera que constituye un error de derecho atribuir validez a la cláusula segunda del conocimiento de embarque, en cuanto por ella se declara que aquellas se sometan a las leyes y tribunales españoles; en efecto, dicha cláusula contraría lo dispuesto en el artículo 1034, que prohíbe incoar procedimientos judiciales en lugares distintos a los especificados en los dos artículos que lo precedente y, por ende y en virtud del artículo 824 de la ley del ramo, debió tenérsela por no escrita; al no declararlo así, la sentencia ha infringido las normas legales citadas, con influencia sustancial en lo dispositivo del fallo, pues dicho error constituye el único sustento de la decisión adoptada." Por su parte, Concha destaca que el artículo 1462 del CG no limita su aplicación a las normas prohibitivas, sino que comprende también a las imperativas - como ocurre en el caso en análisis - , de manera que afecta a todos aquellos resultados institucionales que contravengan la normativa pública. CONCHA (2010), pp. 79-90. Véase también, ROMERO (2017), pp. 163-164; VILLARROEL y VILLARROEL (2015), pp. 403.

57 Véase Monsálvez (2008), pp. 67-69; GuzMán (1997) pp. 582-586; ViLlarroel y ViLLARroel (2015), pp. 444-448. Para un análisis crítico de la jurisprudencia nacional que muestra la confusión entre esta causal y la contravención del orden público, EsPLUGUES (2014), pp. 340-345.

58 En sede de exequatur, véase State Street Bank con Inversiones Errázuriz (2007); Steelcase Inc. (2008). En sede de casación, véase Hochschild con Ferrostaal (2008); M. Limitada con European Industrial (2008); Medtronic Usa con Med Implant (2017). Véase PiCAND y MAHú (2014), pp. 401-409; RoMERO (2017), pp. 166-169; AgUIRREZÁBAL et al (2011), p. 460-461.

59 Tribunal Constitucional (2002). En el voto de mayoría (c. 50º), el Tribunal considera que todo conflicto que involucre un interés público comprometido queda necesariamente sometido al conocimiento y decisión de los tribunales establecidos por la ley chilena. A contrario sensu, puede interpretarse que sólo en la medida en que estemos en presencia de derechos privados disponibles, podrá prorrogarse la competencia a tribunales internacionales o extranjeros.

60 Picand y Mahú (2014)), pp. 439-440; ViaL (2013), pp. 913-914. 
chilenos sea exclusiva. ${ }^{61}$ Como consecuencia de lo anterior, será necesario analizar si la LPDC establece o no una jurisdicción exclusiva de los tribunales chilenos en materia de consumo, porque de hacerlo, los acuerdos de elección de foro extranjero en los contratos internacionales de consumo serían nulos. Para ello, será necesario primero determinar si la LPDC tiene o no reglas de competencia judicial internacional y, en caso afirmativo, indicar cómo deben interpretarse estas reglas.

\section{2 ¿Contempla la LPDG reglas sobre competencia judicial internacional?}

En el Título IV de la LPDC, se encuentran las reglas que determinan los tribunales que están llamados a conocer de los litigios que surjan a raíz de aquellos actos, omisiones o conductas que afecten el ejercicio de los derechos de los consumidores (art. 50 LPDC) y se encargan de establecer también la competencia relativa de estos tribunales. Así, para conocer las acciones de interés individual, la LPDC otorga competencia absoluta a los juzgados de policía local, quienes deben conocer las denuncias presentadas en defensa del interés individual del consumidor (art. 50 A LPDG) ${ }^{62}$ y las acciones ejercidas, a título individual, por parte del consumidor para obtener indemnización por los perjuicios que sufra como consecuencia de la infracción a esta ley (art. 50 H LPDG). Desde de la reforma introducida por la Ley $\mathrm{N}^{\circ} 21.081$, la competencia relativa de los jueces de policía local queda definida por la elección de tribunal que efectúe el consumidor, al momento de interponer su denuncia o demanda. ${ }^{63}$ La LPDG permite al consumidor elegir entre el juzgado de policía local con competencia territorial en el lugar de su domicilio, o aquel que la tenga en el lugar del domicilio del proveedor. ${ }^{64}$ En ambos casos se prohíbe expresamente la prórroga de la competencia por vía contractual ${ }^{65}$ con la finalidad de proteger el interés del consumidor y facilitar su acceso a la justicia. ${ }^{66}$

61 Como señalan Villarroel y Villarroel, el foro exclusivo importa que el Estado, en esa materia, no admitirá más competencia que la de sus propios tribunales. VILLARROEL y VILLARROEL (2015), pp. 390.

62 Por su parte, de conformidad con lo dispuesto en el artículo 50 I de la LPDC, este mismo tribunal será competente para conocer de las acciones por medio de las cuales el consumidor persiga la responsabilidad contravencional del proveedor.

${ }^{63}$ Para un análisis de las nuevas reglas en materia de procedimiento, véase GARCíA (2019), pp. 199-240. En relación con las antiguas reglas de procedimiento, véase CORTEZ (2013), pp. 951-966; BARAHONA (2006), pp. 299-338; VillalobOS (2006), pp. 129-141; y CORTEZ (2004), p. 145.

64 Con todo, entendemos que la regla del domicilio del proveedor debe ser interpretada de una manera consistente con lo dispuesto en el artículo 142 COT, que establece que el domicilio de la persona jurídica demandada corresponde a aquel donde tenga su asiento la corporación o fundación, y que, en caso de que tuviere establecimientos u oficinas en distintos lugares, se considerará aquel en que se celebró el contrato, o que intervino en los hechos que dan origen al juicio.

65 Art 50 A inc. $1^{\circ}$ LPDG. La doctrina ha sustentado la improcedencia de la prórroga de la competencia entre los juzgados de policía local, habida consideración que el artículo 182 COT la admite sólo entre tribunales ordinarios de la misma jerarquía. Véase CORTEZ (2013), pp. 978-979; CORTEZ (2004), pp. 39-40; COLOMBO (2004), p. 505.

66 Véase Informe de la Comisión de Constitución, Legislación, Justicia y Reglamento de la Cámara de Diputados, donde consta la indicación efectuada por la diputada Marisol Turres, que buscó reconocer al consumidor el derecho a demandar ante el tribunal de su domicilio o del domicilio del proveedor, sin admitir 
Si bien en algún momento de la discusión parlamentaria se planteó que estas reglas permitirían definir la jurisdicción internacional de los tribunales chilenos en materia de consumo, ${ }^{67}$ al parecer, este planteamiento se dejó de lado después, porque el texto de la ley no lo menciona, ni existe doctrina ni jurisprudencia que declare aplicables estas reglas a contratos de consumo internacional.

Consideramos que interpretar los artículos 50 A y $50 \mathrm{H}$ de la LPDC como reglas de competencia judicial internacional implicaría introducir un elemento sistemáticamente extraño dentro de la LPDG porque esta ley no aborda las relaciones de consumo internacionales. ${ }^{68}$ Además, ello supondría desconocer la bien establecida diferencia que existe en nuestro sistema legal entre las nociones de jurisdicción y competencia, que define a la segunda como aquella parte de la jurisdicción que corresponde a cada tribunal. ${ }^{69}$ Los artículos 50 A y $50 \mathrm{H}$ de la LPDC lo que buscan es definir cuál de todos los diversos juzgados de policía local chilenos potencialmente competentes, podrá conocer y resolver una controversia, ${ }^{70}$ que se encuentra previamente sometida a la jurisdicción chilena.

Sin embargo, esta situación no obsta a que, ante la ausencia de una norma expresa de competencia judicial internacional en la LPDC que permita definir la cuestión, se interpreten extensiva y teleológicamente estas normas de competencia nacional, de modo que se emplee la conexión razonable que ellas consideran - acorde con un principio de protección - para determinar la competencia internacional del tribunal, y deducir así una regla de jurisdicción aplicable a las relaciones internacionales de consumo. ${ }^{71}$ En todo caso, esta deducción no debe prescindir de las limitantes propias que impone la LPDC en lo que concierne a su ámbito específico de aplicación; ni debe afectar otros valores relevantes para definir la jurisdicción internacional de un tribunal, como la proscripción de foros exorbitantes. ${ }^{72}$

En este sentido, aun recurriendo a la interpretación extensiva de estas normas de la LPDC, parece erróneo entender sin más que sus artículos 50 A y 50 H definen la jurisdicción internacional de los tribunales chilenos conforme con la regla del forum actoris y permiten a cualquier consumidor demandar siempre ante los juzgados de policía local de su domicilio. Lo anterior, porque las disposiciones de la LPDC exigen que quien accione sea un consumidor

que el proveedor pudiera alterar dicha competencia por vía contractual. Con posterioridad, en el Segundo Informe de la Comisión de Economía del Senado, se incorporaron las restricciones vigentes, a través de indicaciones efectuadas por el ejecutivo. Durante la discusión, se destacó que esta regla evita que el proveedor pueda imponer al consumidor la competencia de un tribunal distinto a aquel que corresponda a su domicilio.

${ }^{67}$ Véase nota al pie 44.

68 SEVERín (2019), pp. 972.

69 Véase Colombo (2004), pp. 66-67 y 120-123; Romero (2017), pp. 22-27; Hoyos (2001), pp. 79-82.

${ }^{70}$ GARCí́a (2019), pp. 206-207.

${ }^{71}$ En efecto, ante la ausencia de una regla de competencia judicial internacional, se emplea un procedimiento de extensión, que busca internacionalizar los criterios que subyacen a las reglas internas de competencia. Sin embargo, como bien señalan Villarroel y Villarroel, este proceso no puede ser automático, sino que exige una adaptación de las normas a las circunstancias internacionales concretas del caso. VILLARROEL y VILLARROEL (2015), p. 401. En el mismo sentido, GUZMán (1997), pp. 549-550.

72 Conforme señala Scotti, los foros exorbitantes o forum impropri se caracterizan por carecer de razonabilidad porque su conexión con la situación jurídica es inexistente o mínima. SCOTTI (2017), pp. 203-204. BoGGIANO (2001), pp. 135-136; VilLarRoEl y VillarRoel (2015), pp. 389-390. 
(art. $50 \mathrm{~A}$ y $50 \mathrm{H}$ ) y que lo haga en contra de un proveedor, categorías normativas que están definidas por la propia LPDC, ${ }^{73}$ cuestión que presupone que la relación contractual de consumo se encuentra regido por ella. En el mismo sentido, la imposibilidad de aplicar inmediatamente lo dispuesto en los artículos 50 A y $50 \mathrm{H}$ de la LPDC resulta también del artículo 50 de la LPDC, que determina el marco general de aplicación de las reglas de procedimiento para las denuncias y acciones en protección del interés individual, en referencia a la infracción de las disposiciones de la LPDC. De este modo, no es posible aplicar sus reglas de competencia a pretensiones relativas a una relación contractual de consumo internacional, sin antes haber establecido que dicho contrato internacional de consumo se encuentra dentro del ámbito de aplicación de la LPDG.

Como consecuencia de lo anterior, la jurisdicción de los jueces de policía local chilenos está condicionada a que el contrato internacional de consumo esté sometido a la LPDC chilena. Sin embargo, la LPDG no establece reglas relativas a su aplicación en el espacio, ni se refiere específicamente a los contratos de consumo internacionales. ${ }^{74}$ Por esta razón, la delimitación de su ámbito de aplicación debe efectuarse de conformidad con las reglas generales aplicables a los contratos internacionales. Conforme con la visión tradicional sostenida por la doctrina nacional, los efectos del contrato, o derechos y obligaciones que de él emanan, se someten a la ley chilena cuando el contrato ha de cumplirse en Chile, conforme con los criterios generales establecidos en los artículos 16 inc. $3^{\circ}$ del Código Civil y 113 inc. $1^{\circ}$ del Código de Comercio. ${ }^{75}$ De esta forma, los contratos internacionales de consumo, celebrados o cumplideros en el país, se encuentran sometidos imperativamente a la ley chilena, sin que las partes puedan elegir gobernarlos por un derecho diverso, que contemple normas menos favorables para el consumidor. ${ }^{76}$

Así, a nuestro juicio, el elemento que define internacionalmente la jurisdicción de los tribunales chilenos respecto de acciones promovidas por el consumidor en contra del proveedor, ${ }^{77}$ es la conexión objetiva que existe entre el contrato de consumo celebrado y el ordenamiento jurídico nacional. Como consecuencia de lo anterior, en los casos de consumo internacional estaríamos en presencia de una situación en que la jurisdicción chilena no vendría determinada por el forum actoris del consumidor, o por la regla general actor sequitur forum rei, sino por el forum causae o forum legis, vale decir, por el foro determinado por la ley de

\footnotetext{
73 Véanse artículos $1 \mathrm{~N}^{\circ} 1$ y $1 \mathrm{~N}^{\circ} 2$ LPDC. Estas disposiciones son ampliadas en su aplicación en virtud de lo dispuesto en la Ley $\mathrm{N}^{\circ}$ 20.146. Con todo, como se trata de categorías previstas en la ley chilena, deberán ser resueltas conforme con sus propios estándares. Sobre el concepto de consumidor y su extensión hacia las micro y pequeñas empresas en virtud de la Ley No 20.416, FERNÁNDEZ (2019), pp. 50-52; BARRIENTOS (2019), pp. 1315; TAPIA (2017b), pp. 26-34.

74 SEVERÍn (2019), p. 972.

75 "El efecto natural i propio de la disposición del inciso tercero es que los contratos celebrados en país estranjero con la intención de que se cumplan en Chile, son iguales o se rijen por las mismas reglas que los contratos que se celebren en Chile; pero esta igualdad o semejanza es solo en cuanto a los efectos, o sea, los derechos i obligaciones que producen." FABRES (1892), p. 144; GROB (2014), pp. 234 ss. Con todo, el autor expresamente excluye el análisis de los contratos de consumo; SEVERÍN (2019), p. 972.

76 VIAL (2013) p. 919.

77 En el caso de las acciones interpuestas por el proveedor en contra del consumidor, se aplica la regla general: actor sequitur forum rei.
} 
fondo que rige la relación contractual. ${ }^{78}$ Esta solución armoniza adecuadamente los diversos intereses que se encuentran comprometidos en la determinación de esta jurisdicción internacional. Por una parte, porque ella es consistente con la jurisprudencia chilena que exige la presencia de una conexión suficiente entre el conflicto y el foro nacional para entender que una causa, para los efectos del artículo $5^{\circ}$ del Código Orgánico de Tribunales, se promueve "dentro del territorio de la República" y queda sometida a la jurisdicción nacional. ${ }^{79} \mathrm{Y}$, por otra, porque nos parece una solución acorde con la protección del debido proceso internacional, que evita los foros exorbitantes ${ }^{80}$ y favorece el acceso a la justicia y la tutela judicial efectiva del consumidor. ${ }^{81}$

En efecto, la interpretación en favor del forum legis que proponemos logra eliminar la posibilidad de que los tribunales chilenos sean considerados como un foro exorbitante en el extranjero, porque evita que el proveedor extranjero quede sometido a la jurisdicción nacional en circunstancias que le resultaba imposible de prever la conexión entre su contrato y el foro chileno, dada por una condición objetiva como es la celebración o ejecución del contrato dentro del territorio de la república; 82 al tiempo que garantiza el acceso a la justicia del consumidor, porque reconoce al consumidor, domiciliado en Chile, la facultad de accionar ante los tribunales nacionales, en la medida que los efectos de ese contrato queden sometidos a las reglas de la LPDC. Finalmente, se trata de una solución que evita las conexiones móviles, pues el consumidor no podría alterar unilateralmente la jurisdicción competente en beneficio del foro nacional, después de celebrado el contrato, mediante una modificación de su domicilio. ${ }^{83}$

Con todo, cabe preguntarse si la LPDG establece una jurisdicción exclusiva de los tribunales chilenos para los contratos internacionales de consumo regidos por sus

\footnotetext{
${ }^{78}$ Como destaca Scotti, en este caso existirá una inversión del orden lógico - según el cual primero se determina el foro competente, para que luego el juez establezca el derecho aplicable-, pues la jurisdicción internacional del tribunal dependerá de la aplicación de su derecho material o sustantivo. SCOTTI (2017), p. 210. BogGiano (2011), pp. 125-126.

${ }^{79}$ Rivas Nielsen con Med El Elektro (2013); Romero (2017), pp. 155 y ss.

${ }^{80}$ Con el consiguiente riesgo del abuso jurisdiccional, "cuya sanción más importante es el desconocimiento extranjero de la sentencia dictada por un tribunal que se arroga una jurisdicción exorbitante." BOGGIANO (2011), p. 114; SCOTTI (2017), p. 186.

${ }^{81}$ Véase nota al pie 36.

${ }^{82}$ Según explica Fabres el art. 16 inc. $3^{\circ}$ del CG determina "que si el contrato no se ha celebrado para cumplirse en Chile, sus efectos (derechos i obligaciones) no se rijen por la ley chilena. En consecuencia, aun cuando exista en Chile el objeto material del contrato, por ejemplo, mil fanegas de trigo, si se estipula que se entreguen en el país estraño donde se celebró el contrato o en cualquiera otro país estranjero, i en jeneral, cuando el contrato no se ha celebrado para cumplirse en Chile, sus efectos no se rijen por la lei chilena." FABRES (1892), pp. 144145.

${ }^{83}$ En particular, este es un problema que resultaría de aplicarse directamente a una relación internacional lo dispuesto en los artículos 50 A y $50 \mathrm{H}$ de la LPDC, pues la propia definición de la regla nacional de competencia relativa no establece un momento determinado para definir el domicilio del consumidor a los efectos de fijar la competencia del tribunal (por ejemplo, su domicilio al momento de la celebración del contrato). De seguirse esa interpretación, el resultado sería que el consumidor podría conferir jurisdicción al tribunal chileno por el solo hecho de domiciliarse en el país después de celebrado el contrato, lo que afectaría los intereses del proveedor, quien quedará sometido a un foro sin relación con el contrato celebrado.
} 
disposiciones. De ser así, el acuerdo de elección de foro extranjero sería nulo, por la ilicitud de su objeto, de conformidad con lo dispuesto en el artículo 1462 CC. La pregunta es relevante, pues podría entenderse que la LPDC exige imperativamente que la controversia sea conocida por parte del foro chileno si se califican sus reglas como principios integrantes del orden público internacional chileno. Esta calificación importaría directamente el establecimiento de un límite a la autonomía privada y el reconocimiento de la jurisdicción nacional como un foro imperativo y exclusivo para las acciones y reclamos de consumo. Sin embargo, aunque concordamos en que la normativa de la LPDC forma parte del orden público nacional, no creemos que sea correcto, ni conveniente, concluir de este sólo hecho una regla de jurisdicción exclusiva del foro chileno, que sea aplicable a las pretensiones que nacen de la infracción de contratos internacionales sometidos a la LPDC. La respuesta adecuada a esta pregunta requiere analizar la naturaleza de las pretensiones individuales (querella infraccional y acción civil) que nacen de la infracción a las disposiciones de la LPDC, ${ }^{84}$ para determinar la importancia que tiene la protección del interés público chileno en cada una de ellas.

En efecto, consideramos que la naturaleza sancionatoria de la querella infraccional impide que ésta sea conocida por parte de un tribunal extranjero, pues su objeto es constatar una infracción a la normativa de consumo e imponer una multa a beneficio fiscal. Aunque quien intente este tipo de acción ante el tribunal sea el consumidor, la finalidad de esta querella es propiamente sancionatoria y, en ese carácter, integra el ius puniendi del Estado chileno, aunque con ciertas atenuaciones. ${ }^{85}$ Por esta razón, en este caso nos encontramos en presencia de una materia de jurisdicción exclusiva de los tribunales nacionales y no podrán validarse las elecciones de foro extranjero realizadas por las partes. Esto implica que el proveedor no podrá invocar la sumisión al foro extranjero para evitar que el juzgado de policía local chileno conozca de la querella infraccional sometida a su decisión.

Por el contrario, cuando se trata de la acción civil que nace como consecuencia de la infracción a la normativa de consumo, no se advierte que exista un interés público de la misma intensidad que permita justificar la jurisdicción exclusiva del foro chileno. Así en las

\footnotetext{
${ }^{84}$ La modificación introducida por la Ley $\mathrm{N}^{\circ} 21.081$ permite demandar civilmente sin necesidad de incoar previamente un procedimiento contravencional. GARCía (2019), pp. 201-202. Con todo, incluso antes de la reforma se afirmaba la separación entre ambas pretensiones. CORTEZ (2004), pp. 25-28; CORTEZ (2013), pp. 955-959; PinOCHeT (2012), p. 429.

${ }^{85}$ En particular, es lo que ocurre con las multas a beneficio fiscal establecidas en los artículos 23 inc. $2^{\circ}, 24$ y 25 de la LPDC, las cuales se producen en el contexto de contratos individuales celebrados con el consumidor. Como destaca Pinochet, la exigencia de sustanciación conjunta de la querella infraccional y de la acción civil obedeció a razones de economía procesal, en circunstancias que el conocimiento de la primera fue entregada a los juzgados de policía local, porque su función es precisamente imponer sanciones por las infracciones a ciertas normativas. PiNOCHET (2012), pp. 431-432 y 437. Esta materia forma parte de un "derecho sancionatorio del consumo" que opera a través de sanciones no penales y que la jurisprudencia ha entendido sobre la base de la unidad del ius puniendi, aunque con matices o atenuaciones. SOTO y DuRÁN (2019), p. 245. En similar sentido, ISLER destaca que la acción infraccional es una manifestación del ius puniendi estatal, que normalmente da lugar a multas como la establecida en los artículos 24 y 28 de la LPDC. En este contexto, la función de la responsabilidad es eminentemente punitiva y de prevención, y se trata de una responsabilidad de orden público y de interés general, razón por la cual el SERNAG tiene la misión de velar por el cumplimiento de las disposiciones cuya infracción la genera. ISLER (2019b), pp. 197-199.
} 
acciones de nulidad, de cumplimiento, de cesación, o de indemnización de perjuicios, ${ }^{86}$ el litigio involucra los intereses privados del consumidor y el proveedor. Lo anterior, aun cuando se trate de las acciones de nulidad en materia de cláusulas abusivas, ya que ellas están centradas en la protección del interés particular del consumidor en tanto parte débil de la relación contractual, antes que en el resguardo del interés general de la sociedad. ${ }^{87}$ Por otra parte, puede también argumentarse que no es coherente, por una parte, reconocer al consumidor una amplia facultad de disposición sobre su pretensión - que comprende la posibilidad de someterla al conocimiento de un árbitro, ${ }^{88}$ transigir o conciliar, ${ }^{89} \mathrm{e}$ incluso de renunciar a esta ${ }^{90-}$, y por otra afirmar que la intervención del foro chileno es imperativa y necesaria para la correcta resolución de la controversia conforme con la ley chilena. Además, en estos casos parece no existir un interés primordial del Estado en el resultado de la controversia. Desde una perspectiva internacional, al Estado sólo le podría interesar que no se afecten negativamente las políticas legislativas, los objetivos y los valores fundamentales contenidos en su legislación, que conforman su orden público internacional. ${ }^{91}$ En el caso de los acuerdos de elección de foro incorporados en contratos internacionales de consumo, estas políticas, objetivos y valores, no podrían verse afectados, ni el orden público ser transgredido, cuando esas elecciones de foro extranjero amplíen los derechos del consumidor.

En efecto, nos parece que la propia noción de orden público que subyace en la normativa de consumo debe ser interpretada teleológicamente, ${ }^{92}$ de acuerdo con los fines de la LPDC, cuyas soluciones no buscan excluir del ámbito de la negocialidad contractual determinadas materias, sino corregir las desigualdades que existen entre las partes contratantes, por medio del desarrollo de un estatuto de protección de la parte más débil. Precisamente, sobre esta base puede afirmarse que la LPDC recoge una noción particular de orden público de protección, que se distingue de la del orden público clásico, que busca tutelar los principios esenciales del ordenamiento jurídico del foro. La finalidad de este orden público de protección, en cambio, es más acotada, pues busca proteger los intereses del contratante más débil. $^{93}$ Esto queda reflejado en la protección que le confiere el artículo 4 LPDC, el que declara irrenunciables de manera anticipada los derechos que él establece en beneficio de los consumidores.

Por esta razón, creemos que la recta interpretación de la LPDG debe priorizar la protección y desarrollo de los intereses de la parte protegida, más que la protección de un interés público o de la soberanía nacional en la aplicación abstracta de la ley. Esto es relevante al menos por dos razones. La primera de ellas, porque es consistente con el reconocimiento de la autonomía de las partes en los contratos internacionales y con la protección del

\footnotetext{
86 Véase art. 50 inc. $2^{\circ}$ de la LPDC. Para una revisión en general de las acciones civiles, ISLER (2019B), pp. 199-205.

87 Morales y Veloso (2019), p. 157.

88 Véanse art. 16 inc. $2^{\circ}$ y $3^{\circ}$ de la LPDG. JEQUIER (2020), pp. 57-92.

89 Véase art. $50 \mathrm{H}$ inc. $4^{\circ}$ de la LPDC.

${ }^{90}$ ESPADA (2013), pp. 196-197.

91 SyMEONIDES (2006), p. XLIII.

92 BARrientos (2019), pp. 92-93.

${ }^{93}$ ISLER (2019a), p. 96. TAPIA y VALDIVIA (1999), pp. 38-44.
} 
consumidor, en cuanto actor en el comercio internacional. ${ }^{94} \mathrm{Y}$ la segunda, porque la protección de la LPDG está centrada propiamente en los intereses del consumidor en cuanto contratante débil, lo que implica aceptar todas aquellas soluciones que no afecten el interés de este consumidor, y, más aún, aceptar aquellas que lo favorezcan, aumentando su libertad y protección. ${ }^{95}$

Finalmente, todo esto nos parece consistente con el rol que debe desempeñar el orden público internacional en los modernos sistemas de derecho internacional privado. En efecto, el orden público es una institución que garantiza la protección de las normas o principios legales básicos del foro ${ }^{96}$ que carece de una delimitación precisa de su contenido específico. Por ello, corresponde al intérprete definir su alcance e identificar los principios esenciales que este orden público debe proteger, a fin de dotarlo de un contenido preciso y de aplicarlo a un caso concreto. Esta intrínseca indeterminación del orden público conlleva un riesgo de interpretación expansiva, ${ }^{97}$ tanto a nivel nacional como internacional, por lo que su correcta y justa aplicación debe reconocer ciertos límites. En efecto, consideramos que, en un sistema fundado en el acceso a la justicia y que reconoce a las partes el control de sus pretensiones, el concepto de orden público aplicable a los acuerdos de elección de foro debe ser concordante con aquel desarrollado por nuestra jurisprudencia en otras materias donde está involucrado el reconocimiento de la autonomía, como ocurre en el arbitraje internacional. Esto implica que la contravención al orden público debe interpretarse en forma restrictiva, ${ }^{98}$ de manera que su aplicación quede reservada a declarar nulos o inoponibles actos y acuerdos que infrinjan normas básicas y fundamentales del Estado chileno, ${ }^{99}$ o en los que exista una manifiesta contravención de la ley nacional. ${ }^{100}$

Profundizando en este problema, consideramos que una interpretación que afirme la existencia de una jurisdicción exclusiva de los tribunales chilenos en materia de consumo internacional, como un principio integrante del orden público internacional chileno, puede terminar, en la práctica, por afectar los intereses del consumidor en lo que concierne a sus posibilidades de acceso a la justicia. En efecto, la nota característica de los foros imperativos y exclusivos es que no admiten la prórroga de la competencia por existir un interés público de que el foro retenga el conocimiento de ese asunto. Por ello, en aquellas materias en que existen estos foros exclusivos, se rechazan incluso aquellos acuerdos expresos post litem natam que puedan celebrar las partes con el objeto de declarar competente a un foro extranjero, y

\footnotetext{
${ }^{94}$ Lo que sería una extensión de lo afirmado en relación con la persona, véase nota al pie 19.

95 Severín (2019) p. 972; Vial (2013), p. 919. Por esta misma razón, consideramos que la restricción de la prórroga de la competencia establecida en los artículos 50 A y 50 H LPDC no puede ser interpretada en términos que implique directamente la nulidad de los acuerdos de elección de foro. Esto podrá resultar especialmente relevante, cuando el consumidor decida demandar en el extranjero y luego el sistema chileno deba reconocer esa sentencia.

96 VIAL (2013), p. 916.

97 MARÍn y GARCía (2011), p. 125.

$98 \mathrm{Su}$ interpretación debe ser excepcional, restrictiva, y quedar reservada para los casos evidentes. MARÍN y GARCía (2011), pp. 127-130.

${ }^{99}$ Informe de la Fiscalía Judicial de la I. Corte de Apelaciones de Santiago, consignado en Holdings B. V.y Publicis Groupe Investments con árbitro Don Manuel José Vial Vial (2009).

100 Vergara Varas con Costa Ramírez (2013).
} 
también la prórroga tácita de competencia que puedan ellas efectuar por el hecho de demandar ante un determinado foro extranjero. Considerar que las normas de la LPDG otorgan jurisdicción exclusiva al foro chileno privaría al consumidor de la facultad de demandar en una jurisdicción extranjera - donde puede tener ventajas sustantivas o procesales, en comparación con su situación en el foro chileno-, y, en el caso de haberlo hecho, lo privaría también de la posibilidad de obtener el reconocimiento en Chile de derechos que le hayan sido reconocidos en un fallo emanado de una jurisdicción extranjera, porque éste sería considerado opuesto a la jurisdicción nacional y no ejecutable en Chile. ${ }^{101}$ Con ello, esta interpretación de la normativa de protección del consumidor chilena terminaría, paradojalmente, por privar de derechos al mismo consumidor que pretende proteger. ${ }^{102}$

\subsection{Controles sustantivos a los acuerdos de elección de foro en la LPDG}

La vinculación entre el contrato y la normativa chilena de consumo no sólo será relevante para definir la jurisdicción del tribunal chileno. Adicionalmente, producirá un segundo efecto, pues al contrato de consumo sometido a las disposiciones de la LPDC, le resultarán aplicables los mecanismos sustantivos de protección al consumidor que ésta prevé; ${ }^{103}$ en particular, los relacionados con el control de las cláusulas abusivas en los contratos de adhesión. 104

De acuerdo con lo dispuesto en el artículo 16 letra g) LPDC, se consideran abusivas aquellas cláusulas que "[e]n contra de las exigencias de la buena fe, atendiendo para estos efectos a parámetros objetivos, causen en perjuicio del consumidor un desequilibrio importante en los derechos y obligaciones que para las partes se deriven del contrato." Si bien el artículo 16 letra g) LPDG no proporciona estrictamente una definición legal de cláusula abusiva, ${ }^{105}$ a partir de él se pueden extraer los dos criterios principales, cuya aplicación copulativa, permite considerar una cláusula como abusiva: a) que la incorporación

\footnotetext{
101 Art. $245 \mathrm{~N}^{\circ} 2$ del CPG.
}

102 No se puede olvidar que en esta materia está en juego la protección de los derechos de los particulares y, en concreto, la realización procesal de éstos en el tráfico internacional. Por ello, "cuando se deniega el reconocimiento de una sentencia extranjera [...], las consecuencias inmediatas de dicha decisión no las padece el Estado extranjero sino unos particulares concretos (las partes beneficiadas o perjudicadas por dicha sentencia)." VIRGÓS y GARCIMARTín (2007), p. 41.

103 En los contratos de consumo siempre existe la sospecha de que el consumidor no conoce sus términos y presta un consentimiento "a ciegas". Así, para evitar cláusulas sorpresivas la LPDC contempla reglas formales que buscan resguardar el consentimiento informado por parte del consumidor, y exigen al proveedor que las cláusulas estén redactadas de un modo legible y en español, TAPIA (2017a) p. 85. DE LA MAZA (2012b), p. 132. Finalmente, la sanción por la inobservancia de la carga de escrituración sería la inejecutabilidad de la cláusula, de manera que éstas perderían fuerza obligatoria sólo respecto del proveedor. CONTARDO (2014), p. 127. Véase también TAPIA y VALDIVIA (1999), pp. 66-78.

${ }^{104}$ En los términos del artículo $1 \mathrm{~N}^{\circ} 6$ LPDG, se entiende por contrato de adhesión "aquel cuyas cláusulas han sido propuestas unilateralmente por el proveedor sin que el consumidor, para celebrarlo, pueda alterar su contenido."

105 MORALES (2018), pp. 34-35. 
de la cláusula contraríe los especiales deberes de consideración que deben tenerse las partes, como consecuencia del principio de la buena fe que debe regir su actuación; ${ }^{106}$ y, b) que la cláusula importe un grave desequilibrio en la relación contractual, en perjuicio de los derechos del consumidor. ${ }^{107}$ Esta calificación de abusiva supone un control judicial sustantivo ex post de la cláusula en cuestión, que mira al resultado que tiene su incorporación en el contrato, que opera independientemente del conocimiento que tenga el consumidor respecto de sus efectos, y que prescinde de las razones por las cuales éste haya consentido en ella.

En lo que concierne al primer requisito para que la cláusula sea abusiva, consideramos que, en general, la aplicación objetiva del principio de buena fe lleva a afirmar que existe abuso por parte del proveedor cuando impone una cláusula de elección de foro extranjero al consumidor. Lo anterior, aun cuando pueden darse casos de excepción en que el consumidor preste un consentimiento específico e informado en relación con el acuerdo de elección de foro extranjero, o que exista una conexión real entre el foro elegido y el contrato de consumo. En efecto, tanto en el ámbito internacional, ${ }^{108}$ como en el derecho interno, ${ }^{109}$ la normativa de consumo busca proteger el acceso a la justicia del consumidor, de modo que una cláusula que anticipadamente le impone la carga de litigar en una jurisdicción extranjera puede considerarse contraria a sus razonables expectativas, además de excesivamente desequilibrada y abusiva. Esta conclusión se ve también confirmada, si consideramos que la elección de un foro extranjero puede implicar una renuncia tácita a la protección que confiere la LPDC chilena al consumidor. ${ }^{110}$ Esto último porque el tribunal extranjero designado aplicará, para resolver el litigio, el derecho que sus propias normas de Derecho Internacional Privado le indiquen como aplicables, el que puede ser un derecho extranjero. Por otra parte,

\footnotetext{
${ }^{106}$ Esta buena fe exige que la conducta desarrollada por el proveedor no vaya en desmedro de las expectativas razonables que el consumidor podía tener de la celebración del contrato, lo que importa la exclusión de todas aquellas cláusulas que "contratantes normales, debidamente informados y en condiciones de paridad negocial, no hubiesen pactado.” DE LA MAZA (2012b), p. 140.

107 DE LA MAZA (2012b), p. 139. Con todo, aunque la disposición citada parece incorporar dos parámetros de control - el primero durante la negociación y celebración del acuerdo y el segundo en la revisión de los efectos de la cláusula en cuestión - la exigencia de ambos controles se ha cuestionado. En este sentido, MOMBERG y MORALES sostienen que una cláusula que cause una ventaja injustificada y significativa a favor del proveedor es por si misma incompatible con la buena fe contractual. Para ambos, el elemento fundamental para la aplicación de la regla será la desproporción significativa entre las contraprestaciones de las partes. MOMBERG (2013), p. 18; Morales y Veloso (2019), p. 154; Morales (2018) pp. 38-40. En similar sentido, agrega Campos que "las exigencias de la buena fe se concretan en la exigencia de predisponer un contenido equilibrado, que no entorpezca en sentido alguno la satisfacción de las expectativas que razonablemente alberga el adherente en la ejecución del contrato. De ahí entonces que el solo desequilibrio importante revele, sin necesidad de ninguna otra consideración, la contravención a las exigencias de la buena fe." CAMPOS (2019), p. 241.

108 Sobre la aplicación del control de las cláusulas abusivas a los acuerdos, Álvarez (1992), pp. 137-138.

109 En este sentido, destaca la reforma introducida por la Ley $\mathrm{N}^{\circ} 21.081$, previamente analizada.

110 Sin embargo, la elección de un foro extranjero no entraña necesariamente perjuicio al consumidor puesto que la aplicación de un determinado derecho extranjero, como consecuencia de la elección de ese foro, puede terminar siendo beneficiosa para el consumidor. En este sentido, señala GUARDANS que se podría defender una elección de ley, en la medida que ésta tenga una efectiva vinculación con el contrato y que no sea perjudicial para la parte más débil, siempre en la medida que exista un especial consentimiento por parte del consumidor. Guardans (1992), p. 325. Véase Vial, (2013), p. 919; SEverín (2019) p. 972. Esta solución debe ser concordante con lo expuesto a propósito del orden público internacional.
} 
en lo que respecta al segundo requisito, consideramos que la inclusión de una cláusula que prive al consumidor nacional del acceso al juez nacional previsto por la LPDC importará un desequilibrio importante en la relación contractual, por cuanto, en la práctica, el consumidor verá impedido o gravemente dificultado su acceso al sistema judicial. Esta última situación ocurrirá sea que se considere que el consumidor tiene un derecho a acceder al juez chileno dispuesto en los artículos 50A y 50H de la LPDC, 111 o sea que se considere que solamente tiene un interés de acceder a él de acuerdo con las disposiciones de la ley. ${ }^{112}$

Como se ha expuesto, el control en materia de cláusulas abusivas es siempre ex post, es decir, posterior a la celebración del contrato cuya nulidad se pretende. ${ }^{113}$ Esto excluye, por regla general, un eventual control de legalidad de carácter "preventivo" del acuerdo de elección de foro incorporado por el proveedor extranjero en el contrato de consumo y propuesto al consumidor dentro de un contrato de adhesión. ${ }^{114}$ A pesar de lo anterior, el acuerdo de elección de foro extranjero incorporado en el contrato internacional de consumo no podrá declararse nulo por aplicación de lo dispuesto en el artículo 16 letra g) de la LPDC, si fue objeto de una negociación particular y específica entre el consumidor y el proveedor. En este caso, aun cuando la cláusula resulte "abusiva" en su contenido, carecerá de un requisito indispensable para que opere la protección de la LPDC, como es su incorporación en un contrato de adhesión. Sin embargo, podría aún sostenerse la ineficacia de la elección de foro en el caso de un acuerdo libremente convenido, si los artículos $50 \mathrm{~A}$ y $50 \mathrm{H}$ de la LPDC se interpretan en el sentido de reconocer al consumidor el derecho de recurrir ante el juez nacional, pues en ese evento recibirá aplicación lo dispuesto en el artículo $4^{\circ}$ de la LPDC, que prohíbe la renuncia anticipada de los derechos que la ley establece en beneficio de los consumidores. Con todo, no consideramos adecuada esta interpretación porque, aunque existe doctrina que entiende que esta prohibición no comprende sólo la prohibición de renunciar los derechos subjetivos, sino también las facultades legales que concede la

111 Derecho de acceso al juez chileno que tendría el carácter de irrenunciable anticipadamente, conforme con lo dispuesto en el artículo $4^{\circ}$ LPDC. Aunque problemática, esta interpretación resultaría favorable para el consumidor, pues lo relevaría de la carga de acreditar cuáles son los elementos presentes en el caso, que importan una afectación de sus intereses. Sobre la relación entre la irrenunciabilidad dispuesta en el artículo $4^{\circ}$ de la LPDG y el control de las cláusulas abusivas, MOMBERG (2013), p. 193.

112 Una interpretación de las restricciones que considere la existencia de un interés del consumidor en acceder a la justicia, antes que un derecho a recurrir específicamente ante los tribunales establecidos en la LPDC puede ser relevante, si consideramos su posible extensión hacia aquellas pretensiones no cubiertas por los artículos 50 A y 50 H LPDC. En particular, si se trata de definir una eventual infracción a la regla residual actor sequitur forum rei, cuando quien demanda es el proveedor, lo que podría afectar las posibilidades efectivas de defensa del consumidor.

113 Morales y Veloso (2019), pp. 155-156. En el mismo sentido, destaca Barrientos que en materia de consumo rige la autonomía de la voluntad; no obstante, las cláusulas no negociadas podrán ser objeto de revisión judicial a posteriori. BARRIENTOS (2019), p. 92.

114 Con todo, en la medida que exista una serie de contratos que incorporan esta cláusula, su validez podría ser examinada dentro de un proceso colectivo, iniciado por el SERNAC. Sobre el ejercicio de la acción de nulidad por parte del SERNAC, CARRASCO y CONTARDO (2019), pp. 81-83. En este último caso, no obstante que se hayan celebrado los contratos cuya nulidad se demanda, el examen que efectuará el juez del carácter abusivo de la cláusula será siempre general y abstracto, y no considerará las particulares condiciones en que se celebró cada contrato en cuestión. CAMPOS (2019), p. 270. 
LPDC; ${ }^{115}$ pensamos que existen sólidas razones para entender que el acceso al juez competente no es un derecho irrenunciable en la LPDC. En particular, esto se demuestra en el hecho de que el legislador debió incorporar expresamente en ella una prohibición a la prórroga de la competencia en los contratos de adhesión. ${ }^{116}$

De la misma forma, nos parece que los acuerdos de elección de foro celebrados post litem natam no están abarcados por las restricciones de la LPDG y pueden ser considerados válidos. Esto porque, conforme a lo dispuesto en el artículo $4^{\circ}$ de la LPDC, lo que se encuentra prohibido es la renuncia anticipada a los derechos que ella establece, lo que no obsta a que el consumidor con posterioridad a la celebración del contrato, celebre otros pactos que considere favorables a su interés. Es más, si el consumidor puede disponer de su pretensión y renunciar a ella, no hay razón para impedir que pueda someterla a un tribunal extranjero. Por otra parte, en los acuerdos post litem natam tampoco concurre la razón que justifica la protección del consumidor; ellos no forman parte de un contrato de adhesión y son pactados en instrumentos autónomos, cuando la situación negociadora en que se encuentran las partes no es asimilable a aquella en que se encontraban al momento de celebrar el contrato original de consumo internacional. ${ }^{117}$

Finalmente, consideramos que son plenamente válidos aquellos acuerdos de elección de foro celebrados antes del contrato o incluidos como una cláusula dentro de él, que sólo obliguen al proveedor $-\mathrm{y}$ no al consumidor - a recurrir ante un determinado foro, especialmente, si se trata del foro del domicilio o residencia habitual del consumidor; o aquellos acuerdos que establezcan foros alternativos (no exclusivos) a los cuales pueda recurrir el consumidor, siempre y cuando incluyan el foro de su domicilio o residencia habitual. En este último caso, nos encontramos en presencia de una cláusula que no afecta ex ante derechos irrenunciables del consumidor, y que, en último término, será validada, en sus efectos prácticos, por un acto posterior, como es la decisión libre que tome el consumidor de recurrir a un foro distinto del nacional.

Como consecuencia de lo anterior, consideramos que el acuerdo de elección de foro extranjero será abusivo siempre que integre un contrato de adhesión sometido a la ley chilena, y que tenga por efecto privar anticipadamente al consumidor de la facultad de accionar ante el juez de policía local que establecen los artículos 50 A y $50 \mathrm{H}$ de la LPDC, o bien, en aquellos casos en que altere la regla actor sequitur forum rei y faculte al proveedor a iniciar en contra del consumidor una demanda en un foro distinto a aquel que corresponde al domicilio de este último. En ambos casos, el carácter abusivo del pacto está determinado por la afectación de los intereses del consumidor - expresados en el acceso a la justicia-, de

115 EsPADA, (2013), pp. 195-196.

116 Art. $50 \mathrm{~A}$ y art. $50 \mathrm{H}$ de la LPDC.

117 Una vez que se produce el conflicto, las partes se encuentran en una posición que les permite valorar sus derechos en relación con el tribunal a quien le corresponde intervenir; además de que en ese momento no influirán en el consumidor elementos que distorsionen su decisión, relacionados con la celebración del contrato. Estas son razones que justifican la validez del acuerdo post litem natam y de la sumisión tácita. GONZÁLEZ y MARTín (2011), pp. 172-173. En el mismo sentido, una vez nacido el conflicto, no existe un riesgo de que la parte "fuerte" pueda imponer al consumidor la obligación de comparecer a un determinado tribunal. Véase Tomé y García-Luben (2011), p. 240. El Reglamento Bruselas I bis, la Convención de Lugano y la Ley de derecho internacional privado suiza de 1987 siguen esta solución. 
una manera contraria a la buena fe y a las razonables expectativas que las partes tenían al celebrar el contrato. Este acuerdo de elección de foro podrá ser declarado nulo, sin que esa nulidad afecte al resto del contrato; ${ }^{118}$ y adicionalmente, considerando que se trata de una nulidad fundada en las disposiciones de la LPDC ${ }^{119}$ y que tiene por finalidad proteger a la parte más débil del contrato, ${ }^{120}$ podrá ser invocada por el consumidor no obstante haber celebrado el contrato sabiendo o debiendo saber el vicio que lo invalidaba, ${ }^{121}$ y además, no podrá ser subsanada por el transcurso del tiempo. ${ }^{122}$ Finalmente, en cualquiera de estos casos, además de la acción de nulidad, el interés del consumidor se protege en sede de exequátur, pues la sentencia dictada por un tribunal extranjero que funde su jurisdicción en el acuerdo de elección de foro no podrá ser reconocida en Chile, ya que si la ley nacional considera nulo dicho acuerdo, la Corte Suprema declarará que esa sentencia se opone a la jurisdicción nacional (art. $245 \mathrm{~N}^{\circ} 2$ del CPG).

\section{CONGLUSIONES}

La legislación chilena no aborda sistemáticamente la regulación de los acuerdos de elección de foro en contratos internacionales. Por esta misma razón, no es de extrañar que tampoco exista una reflexión acerca de las consecuencias que tiene su incorporación en contratos de consumo internacionales, y que nuestro derecho no contemple instituciones especiales con miras a resguardar el acceso a la justicia del consumidor internacional. La pregunta por los límites de la autonomía de la voluntad de las partes en materia de competencia judicial internacional supone que previamente haya sido reconocida como un principio fundante del sistema jurisdiccional. Sin embargo, existe un creciente consenso en nuestro derecho acerca de la importancia de esta autonomía como elemento que define la competencia judicial internacional en materia de obligaciones contractuales, la cual ha dado

\footnotetext{
118 Véase art. 16 A LPDC. Desde la perspectiva del derecho del consumo nacional, este es un punto "sobre el cual parece no haber mayor discusión." MoRALES y Veloso (2019), p. 160. Por otra parte, entendemos sobre esta misma base que una discusión sobre la validez del contrato no afecta necesariamente la validez del acuerdo, en virtud de su separabilidad. Como señala BRIGGS, la separabilidad es una técnica que protege el acuerdo de elección de foro de los cuestionamientos que se efectúen a la validez del contrato al que pertenece, y que en principio debe ser definida por la misma ley que rige al contrato. BRIGGS (2008), pp. 12 y 66-70. v. también, VIRGÓS y GARCIMARTíN (2007), pp. 278-279; NYGH (1999), pp. 79-80.

119 BaraONa (2014), p. 233-241; Morales y Veloso (2019), pp. 157-160.

120 Morales y Veloso (2019), pp. 157-160. Por su parte, la calificación de los intereses protegidos en la declaración de nulidad permite preguntarse si ella puede ser declarada de oficio por el juez. En este sentido, se sostiene que el juez podría efectuar esta declaración, sustentado en el carácter imperativo de las normas de consumo y en la existencia de un interés público. CAMPOS (2019), pp. 265-276; CAMPOS (2018), pp. 19-28. Por nuestra parte, consideramos que la operatividad práctica del orden público de protección es incompatible con el reconocimiento de esta facultad. En particular, como señala Baraona, porque una protección abstracta del consumidor podría ser disfuncional a sus concretos intereses, razón que justifica la necesidad de una solicitud de nulidad específica por parte de los interesados. BARAONA (2014), p. 239-240.

${ }^{121}$ Esto implica que en la materia no recibe aplicación la regla nemo auditur propiam turpitudinem allegans dispuesta en el artículo 1683 del CC. Baraona (2014), p. 239; Morales y Veloso (2019), pp. 159; Campos (2019), pp. 263.

122 BARAONA (2014), p. 238.
} 
lugar a una jurisprudencia que progresivamente se ha alejado de las concepciones de la jurisdicción como poder soberano y absoluto del Estado, para ampliar el reconocimiento de la autonomía privada.

Por esta razón, pese a la ausencia de una normativa que específicamente resuelva acerca de la validez de las elecciones de foro realizadas por las partes en contratos internacionales de consumo, consideramos que una interpretación armónica de las normas de derecho internacional privado y de consumo de nuestra legislación permite construir una solución, favorable a su reconocimiento. En particular, porque la LPDC protege el acceso a la justicia de los consumidores nacionales, en el contexto de las relaciones internacionales en que intervengan. Sin embargo, los artículos 50A y 50H de la LPDC no establecen directamente reglas de competencia judicial internacional. Por esa razón, la competencia de los jueces de policía local chilenos estará condicionada a que el contrato internacional de consumo esté sometido a la LPDC chilena, conforme con los criterios generales establecidos en los artículos 16 del Código Civil y 113 del Código de Comercio, que ordenan la aplicación de la ley nacional a los efectos en Chile de los contratos internacionales.

Con todo, que un conflicto quede sometido al foro chileno no importa que la intervención del juez chileno sea necesaria y exclusiva. Si la jurisdicción chilena no es exclusiva, pueden las partes someter la controversia a un foro extranjero. En materia de contratos de consumo internacionales hay buenas razones para considerar que la jurisdicción no es exclusiva, al menos cuando se trata de las acciones civiles que nacen como consecuencia de la infracción de sus disposiciones. En efecto, calificar la jurisdicción de los tribunales chilenos como exclusiva o necesaria sería contradictorio con las diferencias que existen entre el orden público clásico y la noción de orden público de protección, propio de la LPDC, que permite aquellas soluciones favorables al interés del consumidor; a lo que se suma que la calificación de la jurisdicción chilena como exclusiva crea el riesgo de que la intervención del foro chileno en la materia sea considerada exorbitante en el extranjero y vulnere el derecho al juez natural - juez de su domicilio - que tiene el proveedor.

Por las razones expuestas, consideramos que la solución que logra conciliar de mejor manera los fines de protección propios de la normativa de consumo y la importancia de la autonomía de las partes en los contratos internacionales es controlar la validez de las cláusulas de elección de foro extranjero incluidas en contratos de adhesión conforme a los estándares de las cláusulas abusivas que dispone el artículo 16 letra g) de la LPDC. Este control permitirá declarar la nulidad de aquellas cláusulas que afecten gravemente el interés del consumidor y lo obliguen a interponer su demanda civil ante un tribunal extranjero distinto de aquel previsto en los artículos $50 \mathrm{~A}$ y $50 \mathrm{H}$ de la LPDC, cuando el contrato de consumo internacional se encuentre sometido a la ley chilena, bajo la condición siempre de que se trate de un contrato de adhesión. De la misma forma, también permitirá calificar como abusiva aquella cláusula que obligue al consumidor a renunciar a su foro natural, en beneficio del foro del proveedor, cuando sea este último quien demande.

Por el contrario, este mismo control permitirá validar aquellas elecciones de foro que favorezcan el interés del consumidor. Esto sucede - aun en los contratos de adhesión - en aquellas elecciones que lo habilitan para recurrir, ante diversos foros alternativos, siempre que entre ellos se encuentre el de su domicilio; o aquellas elecciones de foro que se hayan 
negociado particularmente entre el consumidor y el proveedor; o aquellas que acuerden las partes ex post, una vez que nació el conflicto. Finalmente, este control de cláusulas abusivas permitirá validar todos los acuerdos de elección de foro que, integrados en un contrato de consumo internacional, limiten el acceso del proveedor a un determinado foro, si esta limitación no perjudica al consumidor.

Consideramos que esta solución e interpretación del alcance jurisdiccional de las normas de la LPDC que valida en ciertos casos las elecciones de foro extranjero en los contratos internacionales de consumo, resulta más justa y acorde no sólo con la protección del acceso a la justicia por parte del consumidor, sino también con una visión del Derecho Internacional Privado y de la jurisdicción internacional fundada más en la protección de la libertad de las personas, que en la defensa de las prerrogativas jurisdiccionales del Estado. 


\section{BIBLIOGRAFÍA GITADA}

AguirrezÁBAL, Maite et al. (2011). "Libre circulación de las sentencias en la litigación procesal civil internacional: un examen desde la justicia procedimental y el debido proceso en el derecho positivo chileno", Revista de Derecho de la Pontificia Universidad Católica de Valparaíso, 2011, XXXVI, pp. 431-472.

Álvarez, Santiago (1992). Condiciones generales en la contratación internacional, La Ley, Madrid.

BARAHONA, Juan (2006). "Procedimiento general de protección de los derechos del consumidor", en: De LA MAZA, I. (coord.), Temas de contratos, Cuadernos de análisis jurídico, III, Universidad Diego Portales, Santiago, 2006, pp. 299-338.

BARAONA, Jorge (2014). "La nulidad de las cláusulas abusivas en la Ley N¹9.496: naturaleza y régimen", en: en: BARRIENTOS, F. (coord.), Condiciones generales de la contratación y cláusulas abusivas, Cuadernos de análisis jurídico, VIII, Ediciones Universidad Diego Portales, 2014, pp. 233-241.

BARRIENTOS, Francisca (2019). Lecciones de derecho del consumidor, Thomson Reuters, Santiago.

Boggiano, Antonio (2001). Curso de derecho internacional privado. Derecho de las relaciones privadas internacionales, Abeledo-Perrot, $3^{\mathrm{a}}$ ed., Buenos Aires.

BRIGGS, Adrian (2008). Agreements on jurisdiction and choice of law, Oxford University Press, Oxford.

Caivano, Roque (2011). El control judicial en el arbitraje, Abeledo Perrot, Buenos Aires.

CAMPOS, Sebastián (2018). "Sobre el poder-deber de declarar de oficio la nulidad de cláusulas manifiestamente abusivas y su aplicabilidad en Chile", Revista de Derecho y Consumo, 2018, $\mathrm{N}^{\circ} 1$, pp. 11-36.

Campos, Sebastián (2019). Control de contenido y régimen de ineficacia de las cláusulas abusivas, Thomson Reuters, Santiago, 2019.

CARrasco, Jaime y CONTARDO, Juan Ignacio (2019). "Ensayo sobre el ejercicio procesal de la ineficacia de forma (artículo 17 LPDC) y fondo (artículos 16, 16A y 16B LPDC) en los contratos por adhesión con consumidores", en: CONTARDO, J. et. al. (coords.), Litigación en materia de consumidores. Dogmática y práctica en la reforma de fortalecimiento al SERNAC, Thomson Reuters, Santiago, 2019, pp. 69-91.

Colombo, Juan (2004). La competencia, Editorial Jurídica de Chile, Segunda edición, Santiago.

Colombo, Juan (1991). La jurisdicción en el derecho chileno, Editorial Jurídica de Chile, Santiago.

ConchA, Ricardo (2010). "El objeto contrario al derecho público. (artículo 1462 del Código Civil)." VV.AA. Fornadas de Derecho Civil IV. Legal Publishing, Santiago, 2010, pp. 7990.

CONTARDO, Juan Ignacio (2014). "Ensayo sobre el requisito de la escrituración y sus formas análogas en los contratos por adhesión regidos por la Ley $\mathrm{N}^{\circ} 19.496$ ”, en: BARRIENTOS, F. (coord.), Condiciones generales de la contratación y cláusulas abusivas, Guadernos de análisis jurídico, VIII, Ediciones Universidad Diego Portales, 2014, pp. 113-127.

CORRAL, Hernán (2006). "La aplicación jurisprudencial de la buena fe objetiva en el ordenamiento civil chileno". en: DE LA MAZA, I. (coord.), Temas de contratos, Cuadernos de análisis jurídico, III, Universidad Diego Portales, Santiago, 2006, pp. 187-226. 
Cortez, Gonzalo (2013). "Artículo 50", en: De la MaZA, I. y Pizarro, C. (dirs.), La protección de los derechos de los consumidores, Thomson Reuters, Santiago, 2013, pp. 951966.

CorTez, Gonzalo (2004). El nuevo procedimiento regulado en la Ley $\mathcal{N}^{\circ} 19.496$ sobre protección de los derechos de los consumidores, Lexis Nexis, Santiago.

DE LA MAZA, Iñigo (2012a). "Contratos de adhesión y cláusulas abusivas ¿Por qué el Estado y no solamente el mercado?" en: BARRIEnTOS, F. et al. (coords.), Consumidores, Abeledo Perrot Thomson Reuters, Santiago, 2012, pp. 1-46.

DE LA MAZA, Iñigo (2012b). "El control de las cláusulas abusivas y la letra G)", en: BARrientos, F. et. al. (coords.), Consumidores, Abeledo Perrot Thomson Reuters, Santiago, 2012, pp. 115-147.

Domínguez, Ramón (2012). Teoría general del negocio jurídico, Editorial Jurídica de Chile, Segunda edición, Santiago.

DreyzIN, Adriana (2015). El derecho internacional privado actual, Tomo I, Zavalia, Buenos Aires.

ESPADA, Susana (2013). "Artículo 4"”, en: DE LA MAZA, I. y PIZARRO, C. (dirs.), La protección de los derechos de los consumidores, Thomson Reuters, Santiago, 2013, pp. 194-200.

EsPlugues, Carlos (2014). "Sobre la aplicación práctica del modelo chileno de reconocimiento y ejecución de resoluciones extranjeras y la necesidad de su reforma", Revista de Derecho de la Pontificia Universidad Católica de Valparaíso, 2014, XLIII, pp. 297353.

FABRES, José Clemente (1892). La lejislación de Chile con relación al derecho internacional privado, Imprenta Cervantes, Santiago.

FEnTIMAN, Richard (2015). International commercial litigation, Oxford University Press, Segunda edición, Oxford.

FERnÁNDEZ, Diego (2005). "What's new in Latin American Private International Law", Yearbook of Private International Law, 2005, vol. 7, pp. 49-67.

FERNÁNDEZ, Felipe (2019). "La tutela de las micro y pequeñas empresas como consumidoras", en: CONTARDO, J. et. al. (coords.), Litigación en materia de consumidores. Dogmática y práctica en la reforma de fortalecimiento al SERNAC, Thomson Reuters, Santiago, 2019, pp. 49-67.

FORNAGE, Anne-Christine (2011). La mise en oeuvre des droits du consommateur contractant. Etude de droit suisse avec des incursions en droit de l'Union européene, en droit anglais, français et allemand, Stämpfli Editions SA, Berna.

Gallegos, Jaime (2010). "Aspectos generales del derecho internacional privado en Chile", Revista del Magíster y Doctorado en Derecho, 2010, N³, pp. 137-186.

GARAU, Federico (2008). Los acuerdos internacionales de elección de foro, Editorial Colex, Madrid.

García, Gonzalo y CONTRERAS, Pablo (2005). "El derecho a la tutela judicial y al debido proceso en la jurisprudencia del tribunal constitucional chileno", Ius et Praxis, 2005, No2, pp. 229-282.

GARCíA, Ramón (2019). "El procedimiento individual de la Ley de protección de los derechos de los consumidores a partir de las modificaciones de la Ley $\mathrm{N}^{\circ} 21.081$ : otra pieza de un rompecabezas que no termina de encajar", en: CONTARDO, J. et. al. (coords.), Litigación en materia de consumidores. Dogmática y práctica en la reforma de fortalecimiento al SERNAC, Thomson Reuters, Santiago, 2019, pp. 199-240. 
GonzÁlez, Jesús María y Martín, Carlos (2011). "Fueros especiales de competencia internacional (III). Contratos de seguro. Contratos con consumidores. Contratos individuales de trabajo (artículos 8 a 21 RB)", en: De LA Oliva, A. (dir) y GASCón, Fernando (coord..), Competencia judicial internacional, reconocimiento y ejecución de resoluciones extranjeras en la Unión Europea, Aranzadi Thomson Reuters, Cizur Menor, 2011, pp. 155-184.

Grob, Francisco (2014). "La ley aplicable a los contratos internacionales en ausencia de elección por las partes", Revista Chilena de Derecho Privado, 2014, vol. 41, N¹, pp. 229265.

GuARDANS, Ignacio (1992). Contrato internacional y derecho imperativo extranjero, Aranzadi, Pamplona.

GuZMán, Diego (2008). "Valor en Chile de las cláusulas contractuales de elección de ley extranjera y de sumisión a los tribunales extranjeros", en: LLANOS, H y PICAND, E., Estudios de derecho internacional. Homenaje al profesor Santiago Benadava, Librotecnia, Santiago, 2008, pp. 219-224.

GuZMán, Diego (1997). Tratado de derecho internacional privado, Editorial Jurídica de Chile, Tercera edición, Santiago.

HAmilton, Eduardo (1966). Solución de conflicto de leyes y jurisdicción, Editorial Jurídica de Chile, Santiago.

HoOK, Mary (2016). The choice of law contract, Hart Publishing, Oxford y Portland.

Hoyos, Francisco (2001). Temas fundamentales de derecho procesal, Lexis-Nexis, Santiago.

ISLER, Érika (2019a). Derecho del consumo. Nociones fundamentales, Tirant Lo Blanch, Valencia.

ISLER, Érika (2019b). "Una aproximación a las acciones derivadas de la Ley N¹9.496 sobre protección de los derechos de los consumidores", en: MORALES, M. (dir.) y MendozA, P. (coord.), Derecho del consumo: Ley, doctrina y jurisprudencia, DER Ediciones, Santiago, 2019, pp. 195-207.

JEQUIER, Eduardo (2020). "Sobre la arbitrabilidad del conflicto de consumo en Chile: insumo básico para un replanteamiento estructural", Revista Chilena de Derecho Privado, 2020, No34, pp. 57-92.

KleIN, Luciane (2013). Protección internacional del consumidor. Procesos de escasa cuantía en los litigios transfronterizos, Editorial B de F, Buenos Aires.

LEIBLE, Stefan (2017). "Mercado interior, comercio electrónico y protección del consumidor", en: LEIBLE, S. Mercado, protección del consumidor y uniformización del derecho, Ediciones Olejnik, Santiago, 2017, pp. 13-39.

LóPEz, Edgardo (2015). Manual de derecho internacional privado, Abeledo Perrot, Buenos Aires.

MARÍn, Juan Carlos y GARCíA, Rolando (2011). "El concepto de orden público como causal de nulidad de un laudo tratándose de un arbitraje comercial internacional", Revista de Derecho Universidad Austral, 2011, XXIV, N¹, pp. 117-131.

MomberG, Rodrigo (2013a). "Artículo 4o", en: De la MAZA, I. y PizArro, C. (dirs.), La protección de los derechos de los consumidores, Thomson Reuters, Santiago, 2013, pp. 190193.

MOMBERG, Rodrigo (2013b)."El control de las cláusulas abusivas como instrumento de intervención judicial en el contrato”, Revista de Derecho Universidad Austral, 2013, vol. 26, $\mathrm{N}^{\circ}$, pp. 9-27. 
Monsálvez, Aldo (2008). "Validez de las cláusulas de electio forum en los contratos internacionales. A propósito del caso 'State Street Bank Trust v. Inversiones Errázuriz Limitada", en: LlanOs, H y PiCAND, E., Estudios de derecho internacional. Homenaje al profesor Santiago Benadava, Librotecnia, Santiago, 2008, pp. 225-239.

Monsálvez, Aldo (2010). Derecho internacional privado, Editorial Metropolitana, Santiago.

Monsálvez, Aldo (2008). Reconocimiento y ejecución en Chile de sentencias extranjeras, Legal Publishing, Santiago.

Morales, María Elisa y Veloso, Franco (2019). "Cláusulas abusivas en la Ley №19.496. Ley, doctrina y jurisprudencia”, en: MORALes, M. (dir.) y MendozA, P. (coord.), Derecho del consumo: Ley, doctrina y jurisprudencia, DER Ediciones, Santiago, 2019, pp. 149-167.

MORALES, María Elisa (2018). Control preventivo de cláusulas abusivas, DER Ediciones, Santiago. Nygh, Peter (1999). Autonomy in international contracts, Clarendon Press, Oxford.

PICAND, Eduardo y MAHÚ, Pablo (2014). "La 'internacionalidad' de los contratos", en: PiCAND, E., (coord.), Estudios de derecho internacional privado. Chileno y comparado, Legal Publishing Thomson Reuters, Santiago, 2014, p. 395-436.

PINOCHET, Ruperto (2012). “¿Es la condena infraccional requisito de la indemnización de perjuicios regulada en la Ley N¹9.496? Un error histórico”, en: ElORRIAGA, Fabián (coord..), Estudios de derecho civil. VII Jornadas Nacionales de Derecho Civil, Legal Publishing, Santiago, 2012, pp. 427-440.

PizArro, Carlos (2012). "La eficacia del control de las cláusulas abusivas en el derecho chileno", en: BARrientos, F. et al. (coords.), Consumidores, Abeledo Perrot Thomson Reuters, Santiago, 2012, pp. 47-73.

Ramírez, Mario (2013). Derecho internacional privado, Legal Publishing Thomson Reuters, Santiago.

Romero, Alejandro (2017). Curso de derecho procesal civil. Los presupuestos procesales relativos al órgano jurisdiccional y a las partes, Tomo II, Thomson Reuters, Tercera edición, Santiago.

ScotTI, Luciana (2017). Manual de derecho internacional privado, Thomson Reuters La Ley, Buenos Aires.

SEverín, Gonzalo (2019). "La potencial aplicación de la Ley N 19.496 a los contratos de servicios de almacenamiento en la nube", en: GÓMEZ DE LA TORRE, M. et. al. (eds.), Estudios de derecho civil XIV, Thomson Reuters, Santiago, 2019, pp. 959-980.

Soto, Pablo y DuRÁn, Carolina (2019). "El ámbito infraccional en el derecho del consumo: práctica jurisdiccional y modificaciones introducidas por la Ley $\mathrm{N}^{\circ} 21.081$ ”, en: Contardo, J. et. al. (coords.), Litigación en materia de consumidores. Dogmática y práctica en la reforma de fortalecimiento al SERNAC, Thomson Reuters, Santiago, 2019, pp. 241-282.

SYMEONIDES, Symeon (2006). "Sobre teleología, intereses estatales y pluralismo en el derecho aplicable: en memoria afectuosa de Friedrich K. Juenger", Prólogo, en: JuENGER, Friedrich, Derecho internacional privado y justicia material, Editorial Porrúa, Ciudad de México, pp. XXXIX-IL.

TAPIA, Mauricio y VaLdIVIA, José Miguel (1999). Contrato por adhesión. Ley $\mathcal{N}^{\circ} 19.496$. Editorial Jurídica de Chile, Santiago.

TAPIA, Mauricio (2017a). Protección de consumidores. Revisión crítica de su ámbito de aplicación, Rubicón, Santiago. 
TAPIA, Mauricio (2017b). "Medios electrónicos: formación del contrato y protección de la intimidad del consumidor en Chile", en: Pérez, L. (coord.), Contratación electrónica y protección de los consumidores. Una visión panorámica, Editorial Reus, Madrid, 2017, pp. 7599.

Tomé, José Antonio y García-Luben, Paloma (2011). "La prórroga de la competencia internacional (artículos 23 y 24 RB)", en: DE LA OLIVA, A. (dir) y GASCÓn, Fernando (coord..), Competencia judicial internacional, reconocimiento y ejecución de resoluciones extranjeras en la Unión Europea, Aranzadi Thomson Reuters, Cizur Menor, 2011, pp. 213-243.

ViAL, María Ignacia (2013). "La autonomía de la voluntad en la legislación de derecho internacional privado", Revista Chilena de Derecho, 2013, vol. 40, N 3, pp. 891-927.

VillalobOS, Sergio (2006). "Competencia y procedimiento de la ley de protección a los consumidores en los juzgados de policía local”, en: BARAONA, J. y LAGOS, O. (edits.), La protección de los derechos de consumidores en Chile, Cuadernos de Extensión Jurídica, Universidad de los Andes, 2006, pp. 129-141.

Villarroel, Carlos y Villarroel, Gabriel (2015). Derecho internacional privado, Editorial Jurídica de Chile, Santiago, 2015.

VIRGós, Miguel y Garcimartín, Francisco (2007). Derecho procesal civil internacional. Litigación internacional. Civitas Thomson Reuters, Segunda edición, Cizur Menor. 


\section{LEGISLAGión GitAdA}

\section{Argentina:}

Código Civil y Comercial, de 2015.

\section{Chile:}

Código Civil, de 14 de diciembre de 1855.

Código de Comercio, de 23 de noviembre de 1865.

Código de Procedimiento Civil, de 30 de agosto de 1902.

Código Orgánico de Tribunales, de 9 de julio de 1943.

D.L. N².349, establece normas sobre contratos internacionales para el sector público, de 28 de octubre de 1978.

Ley $\mathrm{N}^{\circ} 21.081$, modifica ley $\mathrm{N}^{\circ} 19.496$, sobre protección de los derechos de los consumidores, de 13 de septiembre de 2018.

Ley $\mathrm{N}^{\circ} 19.971$, sobre arbitraje comercial internacional, de 29 de septiembre de 2004.

Ley $\mathrm{N}^{\circ} 19.496$, establece normas sobre protección de los derechos de los consumidores, de 7 de marzo de 1997.

\section{Suiza:}

Ley federal sobre el derecho internacional privado, de 18 de diciembre 1987.

\section{Unión Europea:}

Reglamento (UE) N¹215/2012, relativo a la competencia judicial, el reconocimiento y la ejecución de resoluciones judiciales en materia civil y mercantil (Bruselas I bis).

\section{Tratados Internacionales:}

Código de Bustamante, La Habana 1928.

Convención sobre el Reconocimiento y la Ejecución de las Sentencias Arbitrales Extranjeras, Nueva York 1958.

Convenio relativo a la competencia judicial, el reconocimiento y la ejecución de resoluciones judiciales en materia civil y mercantil de 2007 (Convenio de Lugano). 


\section{JURisprudenGia GitTADA}

\section{Ghile:}

CORTE SuPREMA (1905). Sentencia de 20 de diciembre de 1905.

A.7. Broom con Exportadora Frutícola (1999). Corte Suprema, 25 de enero de 1999, Rol No 6831998.

Tribunal Constituaional (2002). Requerimiento de inconstitucionalidad respecto del Estatuto de Roma de la Corte Penal Internacional, 8 de abril de 2002, Rol No 34602.

State Street Bank con Inversiones Errázuriz (2007). Corte Suprema, 14 de mayo de 2007, Rol Nº 2349-2005.

Hochschild con Ferrostaal (2008). Corte Suprema, 22 de enero de 2008, Rol No 3247-2006.

Steelcase Inc. (2008). Corte Suprema, 25 de marzo de 2008, Rol No 5742-2005.

M. Limitada con European Industrial (2008). Corte Suprema, 28 de julio de 2008, Rol № 20262007.

Holdings B.V. y Publicis Groupe Investments con árbitro Don Manuel José Vial Vial (2009). Corte de Apelaciones de Santiago, 4 de agosto de 2009, Rol No 9134-2007.

Rivas Nielsen con Med El Elektro (2013). Corte Suprema, 10 de abril de 2013, Rol No 5969-2011.

Vergara Varas con Costa Ramírez (2013). Corte de Apelaciones de Santiago, 9 de septiembre de 2013, Rol N 1971-2012.

Medtronic Usa con Med Implant (2017). Corte Suprema, 2 de marzo de 2017, Rol N 479232016. 